\title{
On the Feasibility of Imaging Carbonatite-Hosted Rare Earth Element Deposits Using Remote Sensing*
}

\author{
David A. Neave,,${ }^{1,+, * * *}$ Martin Black, ${ }^{2,3}$ Teal R. Riley, ${ }^{2}$ Sally A. Gibson, ${ }^{1}$ Graham Ferrier, ${ }^{3}$ Frances Wall, ${ }^{4}$ \\ and Sam Broom-Fendley ${ }^{4}$ \\ ${ }^{1}$ Department of Earth Sciences, University of Cambridge, Downing Street, Cambridge CB2 3EQ, United Kingdom \\ ${ }^{2}$ British Antarctic Survey, High Cross, Madingley Road, Cambridge CB3 OET, United Kingdom \\ ${ }^{3}$ Department of Geography, Environment and Earth Sciences, University of Hull, Hull HU6 7RX, United Kingdom \\ ${ }^{4}$ Camborne School of Mines, College of Engineering, Mathematical and Physical Sciences, University of Exeter, \\ Penryn Campus, Cornwall TR10 9FE, United Kingdom
}

\begin{abstract}
Rare earth elements (REEs) generate characteristic absorption features in visible to shortwave infrared (VNIR$\mathrm{SWIR}$ ) reflectance spectra. Neodymium $(\mathrm{Nd})$ has among the most prominent absorption features of the REEs and thus represents a key pathfinder element for the REEs as a whole. Given that the world's largest REE deposits are associated with carbonatites, we present spectral, petrographic, and geochemical data from a predominantly carbonatitic suite of rocks that we use to assess the feasibility of imaging REE deposits using remote sensing. Samples were selected to cover a wide range of extents and styles of REE mineralization, and encompass calcio-, ferro- and magnesio-carbonatites. REE ores from the Bayan Obo (China) and Mountain Pass (United States) mines, as well as REE-rich alkaline rocks from the Motzfeldt and Ilímaussaq intrusions in Greenland, were also included in the sample suite. The depth and area of $\mathrm{Nd}$ absorption features in spectra collected under laboratory conditions correlate positively with the $\mathrm{Nd}$ content of whole-rock samples. The wavelength of $\mathrm{Nd}$ absorption features is predominantly independent of sample lithology and mineralogy. Correlations are most reliable for the two absorption features centered at $\sim 744$ and $\sim 802 \mathrm{~nm}$ that can be observed in samples containing as little as $\sim 1,000 \mathrm{ppm} \mathrm{Nd}$. By convolving laboratory spectra to the spectral response functions of a variety of remote sensing instruments we demonstrate that hyperspectral instruments with capabilities equivalent to the operational Airborne Visible-Infrared Imaging Spectrometer (AVIRIS) and planned Environmental Mapping and Analysis Program (EnMAP) systems have the spectral resolutions necessary to detect $\mathrm{Nd}$ absorption features, especially in high-grade samples with economically relevant REE accumulations $(\mathrm{Nd}>30,000 \mathrm{ppm})$. Adding synthetic noise to convolved spectra indicates that correlations between Nd absorption area and whole-rock Nd content only remain robust when spectra have signal-to-noise ratios in excess of $\sim 250$ : 1. Although atmospheric interferences are modest across the wavelength intervals relevant for $\mathrm{Nd}$ detection, most REE-rich outcrops are too small to be detectable using satellite-based platforms with >30-m spatial resolutions. However, our results indicate that $\mathrm{Nd}$ absorption features should be identifiable in high-quality, airborne, hyperspectral datasets collected at meter-scale spatial resolutions. Future deployment of hyperspectral instruments on unmanned aerial vehicles could enable REE grade to be mapped at the centimeter scale across whole deposits.
\end{abstract}

\section{Introduction}

\section{Rare earth element deposits and reflectance spectroscopy}

Carbonatites, classified as rocks with $>50 \%$ primary magmatic carbonate (Le Maître, 2002), and the alkaline igneous rocks with which they are often associated are the primary source of rare earth elements (REEs), and will remain so for the foreseeable future (Wall, 2014). With notable exceptions, such as the relatively extensive Bayan Obo and Mountain Pass deposits in China and the United States, respectively (Drew et al., 1990; Castor, 2008; Yang et al., 2011; Smith et al., 2015), carbonatite-hosted REE deposits are often small in areal extent

\footnotetext{
+ Corresponding author: e-mail, d.neave@mineralogie.uni-hannover.de

"Supplementary Appendices to this paper are available at http://economicgeology.org/ and at http://econgeol.geoscienceworld.org/.

* Present address: Institut für Mineralogie, Leibniz Universität Hannover, Callinstr. 3, 30167 Hannover, Germany.
}

but high in grade, i.e., have a total rare earth oxide content $(\Sigma$ REO) $>1$ wt \% (Chakhmouradian and Zaitsev, 2012; Wall, 2014). This enrichment is largely the result of late-stage, fluiddominated, carbothermal processes that concentrate REEs in dikes and veins on the meter to tens-of-meter scale during the last stages of emplacement and cooling (Wall and Mariano, 1996; Wall and Zaitsev, 2004; Mitchell, 2005). Conversely, while major alkaline igneous rock-hosted REE deposits, such as Khibiny (also spelled Khibina in the geologic literature) and Lovozero in Russia, can be large in size, they are generally lower grade than their carbonatite counterparts $(\Sigma$ REO $<1$ wt \%; Wall, 2014). The high concentration of REEs in carbonatites makes them well suited for developing exploration and mapping strategies that exploit diagnostic features in the reflectance spectra of REE-rich materials (e.g., Rowan et al., 1986). In this contribution, we discuss the feasibility of imaging primarily carbonatite-hosted REE deposits by hyperspectral remote sensing at visible and near- to shortwave infrared 
(VNIR-SWIR) wavelengths ( $\lambda=400-2,500 \mathrm{~nm}$ ), using both airborne- and satellite-based platforms.

It is well established that a number of lanthanide elements exhibit strong, narrow absorption features in their reflectance spectra (Adams, 1965). Investigating the mechanisms by which spectral absorption features are generated is beyond the scope of this study and detailed discussions of REE spectroscopy are best found in the physical and chemical literature (e.g., Dieke, 1970; Görller-Walrand and Binnemans, 1998). In summary, absorptions characteristic of lanthanide elements are thought to arise from $4 f-4 f$ intraconfigurational electron transitions that result from the $4 f$ shell (radius $\sim 0.3 \AA$ ) being partially shielded by the $5 s$ and $5 p$ shells (radius $\sim 2$ and $1 \AA$, respectively) and thus largely nonparticipatory in bonding (Liu, 2005). REE absorption features are therefore elemental in nature rather than vibrational; they depend on the absolute concentration of REE atoms rather than on their bonding environments (Clark, 1995). While the identification of REEs in mineral and rock spectra is theoretically straightforward, with the notable exceptions of monazite-(Ce), bastnäsite$(\mathrm{Ce})$, parisite- $(\mathrm{Ce}$,$) and synchysite- (\mathrm{Ce})$, there are few published REE-rich reference spectra currently available to the remote sensing community (Fig. 1; Clark et al., 2007; Turner et al., 2014). The most complete presentation of REE-bearing rock spectra remains that of Rowan et al. (1986), who provided VNIR-SWIR spectra from four carbonatite-alkaline complexes in North America (Mountain Pass, Oka, Iron Hill, and Gem Hill), albeit in nondigital form.

As reviewed by Turner et al. (2014), a number of REErich carbonatite and alkaline centers have been successfully imaged using both space- and airborne reflectance spectroscopy. For example, lithologic maps of Mountain Pass in the United States and Khanneshin in Afghanistan have been produced using multispectral Advanced Spaceborne Thermal Emission and Reflection Radiometer (ASTER) instrument (Rowan and Mars, 2003; Mars and Rowan, 2011). However, the coarse spatial and spectral resolutions of satellite-based multispectral instruments severely limit their ability to detect REE absorption features: the only potential identification of REE-rich material from satellite data published to date was at Mountain Pass (Rowan and Mars, 2003). Mapping REErich rocks at finer spatial and spectral resolutions has also been carried out using airborne hyperspectral instruments. Examples include mapping the Iron Hill carbonatite-alkaline complex in the United States with the hyperspectral Airborne Visible-Infrared Imaging Spectrometer (AVIRIS) instrument (Rowan et al., 1995) and the Sarfartoq carbonatite complex in Greenland with the HyMap ${ }^{\circledR}$ system (Bedini, 2009). Despite the presence of characteristic REE absorption features in the reflectance spectra of field samples, no REE absorptions were reported from either of these AVIRIS and HyMap ${ }^{\circledR}$ datasets (Rowan et al., 1995; Bedini, 2009). Nevertheless, Nd and Sm absorptions have been reported in AVIRIS spectra collected over the Sulphide Queen area of Mountain Pass, thereby demonstrating the potential role of hyperspectral remote sensing in imaging REE deposits (Rowan and Mars, 2003). Furthermore, Boesche et al. (2015) successfully delimited high Nd occurrences in a monazite-mineralized outcrop of the Fen complex in Norway using a ground-based HySpex hyperspectral imaging system.

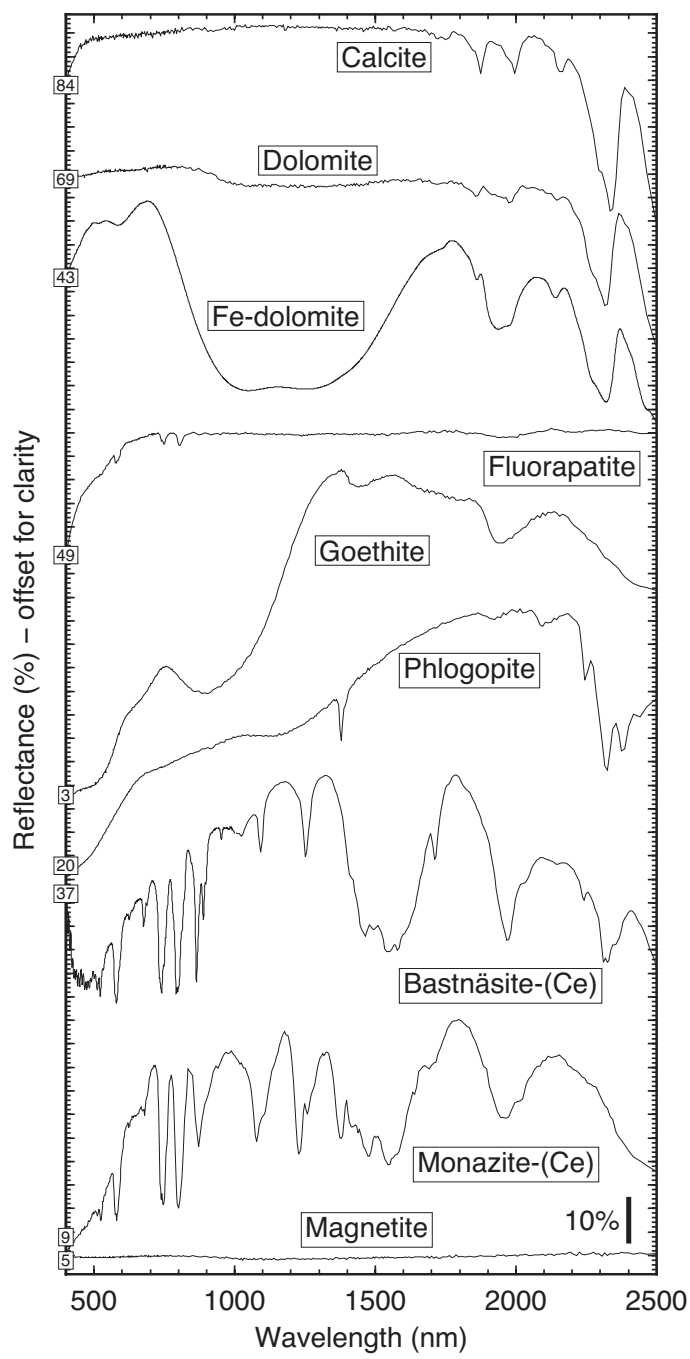

Fig. 1. Reference VNIR-SWIR spectra from common minerals found in REE-rich carbonatites. All spectra are sourced from the USGS spectral library (Clark et al., 2007), apart from the spectrum for bastnäsite that is from Turner et al. (2014). Note the complexity of bastnäsite-(Ce), monazite-(Ce), and fluorapatite spectra that result from REE-related absorptions. Deep Nd absorption features are observed within the 500 - to 900 -nm wavelength interval. Absolute reflectance values are shown at $400 \mathrm{~nm}$.

As hyperspectral mapping capabilities and image processing techniques continue to improve, characterizing mineral deposits using reflectance spectroscopy will become an evermore robust method. For example, the next generation of remote sensing satellites such as the Environmental Mapping Program (EnMAP) will carry spaceborne Earth observation fully into the hyperspectral era (Stuffler et al., 2007; Guanter et al., 2015). However, many questions relating to the identification of REE deposits by remote sensing remain largely unanswered. First, what are the detection limits for identifying REEs in carbonatites and alkaline igneous rocks by reflectance spectroscopy under ideal conditions, i.e., how well do spectral properties correlate with REE grade? Second, do deposit lithology and mineralogy affect the ability to resolve REEs? Third, under what conditions might REE absorption features be resolvable by various classes of remote sensing instrument? 


\section{Approach and scope}

Igneous rocks classified as carbonatites can be generated by a range of petrologic processes (Mitchell, 2005): by low-degree melting of a mantle source (Wallace and Green, 1988; Harmer and Gittins, 1998); by extensive fractional crystallization of carbonated alkaline magmas (Gittins, 1989); and by liquid immiscibility between carbonate and silicate melts (Freestone and Hamilton, 1980; Brooker and Kjarsgaard, 2011). The petrogenesis of alkaline rocks can be equally diverse (Fitton and Upton, 1987) and is often closely linked with the generation of carbonatites (Woolley and Kjarsgaard, 2008). Carbonatites and alkaline igneous rocks are often compositionally variable both within and between magmatic centers and are frequently associated with extensive fenites and contact aureoles. The crystallization of REE minerals generally occurs late in the emplacement history of carbonatites and is largely secondary in nature (Wall and Mariano, 1996). Notable exceptions include the growth of primary bastnäsite-(Ce) at Mountain Pass (Mariano, 1989) and burbankite at Khibina (Zaitsev et al., 2002).

We present reflectance spectra collected from a range of well-characterized carbonatites and carbonatite-related REE ores, as well as from two alkaline igneous centers in Greenland: Motzfeldt and Ilímaussaq. Our sample suite includes samples from currently active REE mines (Bayan Obo in China, Mountain Pass in the United States, and Mount Weld in Australia), as well as samples from exploration projects with significant future mining potential (Ilímaussaq in Greenland). The reflectance spectra presented here significantly expand the spectral library of REE-rich reference material available to the remote sensing community from mineral spectra to spectra on the whole-rock scale (cf. Rowan et al., 1986; Clark et al., 2007; Turner et al., 2014). Furthermore, we use petrographic, geochemical, and spectral information from the same hand specimens to investigate relationships between spectral features, REE grade, and mineral assemblage. Nevertheless, our new spectra are presented with two important caveats. First, although analytical strategies were designed to mitigate the effects of sample heterogeneity at the hand specimen scale, the extreme petrologic variability present within carbonatite and alkaline complexes means that the spectral properties we measure cannot simply be expanded from single samples to the outcrop scale; individual hand specimens are not perfectly representative of their host complexes. Second, the petrographic and geochemical data we present have been collected primarily to contextualize spectral data: placing our samples within a detailed petrogenetic framework for each magmatic system is beyond the scope of this study.

\section{Sample Sources}

Carbonatites and REE ores from the following locations were sourced from the Natural History Museum in London: Bayan Obo in China, Uyaynah in the United Arab Emirates, and Fort Portal in Uganda. Carbonatites from the following locations were sourced from collections at Camborne School of Mines, University of Exeter: Oka and St. Honoré in Canada, Kangankunde, Tundulu, and Songwe in Malawi, Fen in Norway, Jacupiranga in Brazil, Kaiserstuhl in Germany, Mount Weld in Australia, and Phalaborwa in South Africa. Carbonatites from Tororo and Sukulu in Uganda, Chilwa Island and
Kangankunde in Malawi, Mountain Pass in the United States, Panda Hill in Tanzania, and Sokli in Finland were sourced from the Harker Collection at the University of Cambridge. Carbonatites and alkaline rocks from Qeqertaasaq, Tikiusaaq, and Ilímaussaq in Greenland were obtained from collections at the University of St Andrews. Alkaline igneous rocks from Motzfeldt in Greenland were supplied by SRK Consulting (UK) Ltd. The geographic distribution of these samples is summarized in Figure 2.

\section{Analytical Methods}

VNIR-SWIR reflectance spectra were collected from a total of 42 hand specimens during the course of this study. On the basis of sample availability and VNIR-SWIR REE absorption strengths, different combinations of analyses were carried out on different samples (Tables 1-5 document which analyses were performed on each sample). Thermal infrared (thermal IR; $\lambda=$ 8-15 $\mu \mathrm{m}$ ) reflectance spectra were also collected for a subset of 20 samples; absorptions at thermal IR wavelengths can be used to characterize and map the presence of different rock-forming mineral groups such as silicates, carbonates, and phosphates and can thus play a role in delimiting carbonatite complexes (Christensen et al., 2000; Ninomiya et al., 2005; Mars and Rowan, 2011). Whole-rock compositions of 13 samples were collated from published datasets (Woolley et al., 1991; Eby et al., 2009) collated from previously collected but unpublished datasets or supplied by industrial collaborators (SRK Consulting (UK) Ltd.). New whole-rock data were acquired for a additional 18 samples that span much of the petrologic variability present within our sample suite. Mineral assemblages were determined using optical and electron microscopy, except where supplied by collaborators or available in the literature.

\section{Petrography and microscopy}

Thin sections were investigated using a petrographic microscope and an FEI Quanta 650F QEMSCAN in the Department of Earth Sciences at the University of Cambridge. Backscattered electron (BSE) images were collected on the QEMSCAN, using an accelerating voltage of $20 \mathrm{kV}$ and a working distance of $13 \mathrm{~mm}$. Optical phase identification was assisted by using the Bruker XFlash electron dispersive X-ray (EDX) spectroscopy system integrated into the QEMSCAN, with counting times of 15 to $30 \mathrm{~s}$ on both spectrometers. Particular care was taken during sample preparation to ensure that chips taken for thin section production were representative of the surfaces analyzed spectroscopically.

\section{$X$-ray fluorescence spectroscopy}

A total of 18 whole-rock samples were analyzed by X-ray fluorescence spectrometry $(\mathrm{XRF})$ for major and trace elements. Samples were cut into 10 - to $15-\mathrm{cm}^{3}$ blocks, washed in distilled water, and dried prior to crushing in a steel jaw crusher and powdering in an agate ball mill in the Department of Earth Sciences at the University of Cambridge. Fused glass disks and pressed powder pellets were prepared for major and trace element analyses on a PANalytical Axios-Advanced XRF spectrometer in the Department of Geology at the University of Leicester.

Fused glass disks were prepared at the University of Leicester using sample powders that had been dried overnight in 


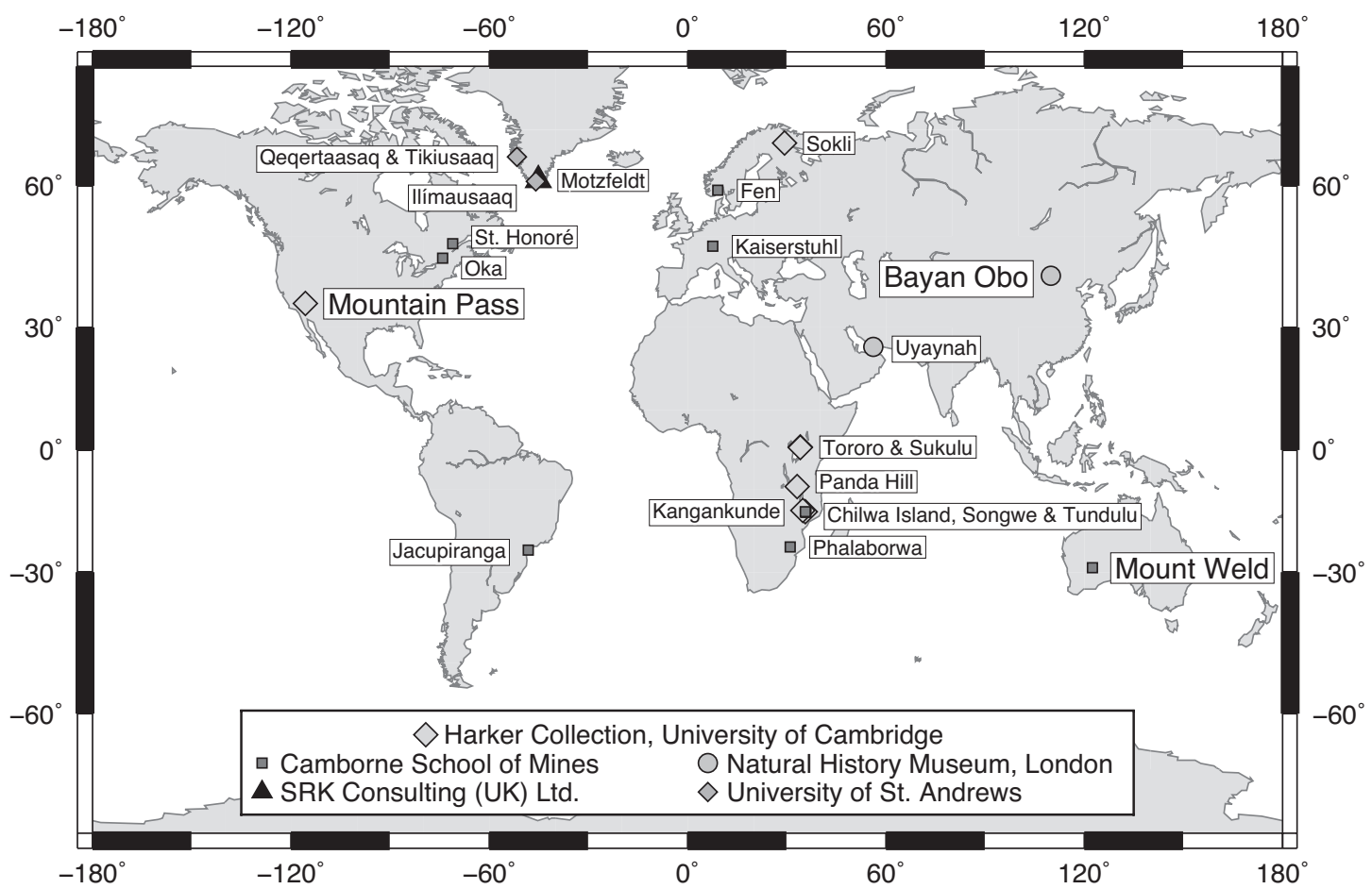

Fig. 2. Map showing the geographic distribution of samples used in this study, as well as the collections from which they were sourced. Bayan Obo, Mountain Pass, and Mount Weld represent currently active REE mine sites and are labeled in a larger font.

order to remove adsorbed water. Loss on ignition (LOI) values were calculated by igniting $\sim 3 \mathrm{~g}$ of each sample in ceramic crucibles at $950^{\circ} \mathrm{C}$, apart from the kakortokite sample from Ilímaussaq that was ignited in a disposable LECO crucible at $750^{\circ} \mathrm{C}$ because of its low solidus temperature. Fusion disks of carbonate-rich samples with high LOI values (LOI $=10-40 \mathrm{wt} \%$ ) were then prepared from $0.6 \mathrm{~g}$ of nonignited powder and $3 \mathrm{~g}$ of lithium tetraborate flux that were melted in a Pt-Au crucible over a Spartan burner and cast into a Pt-Au mold. Carbonate-poor samples with low LOI values (LOI $<10$ wt \%) were prepared from $0.6 \mathrm{~g}$ of ignited powder and $3 \mathrm{~g}$ of lithium metaborate flux.

Powder pellets were prepared at the University of Cambridge by mixing $10 \mathrm{~g}$ of each sample powder with approximately 20 drops of binding agent (2\% polyvinyl alcohol solution) in a clean glass beaker. This mixture was then placed in a die and subjected to a pressure of $15 \mathrm{t} / \mathrm{in}^{2}$ to form smooth, well-compacted pellets for analysis.

\section{VNIR-SWIR reflectance spectroscopy}

VNIR-SWIR $(\lambda=400-2,500 \mathrm{~nm})$ reflectance spectra were collected using an Analytical Spectral Device (ASD)'s FieldSpec Pro FR spectroradiometer at the Natural Environment Research Council Field Spectroscopy Facility at the University of Edinburgh. The ASD spectroradiometer has a spectral range of 350 to $2,500 \mathrm{~nm}$, although data from the shortest wavelengths $(350-400 \mathrm{~nm})$ were found to be noisy over the integration times used ( 25 cycles of $17 \mathrm{~ms}$ per measurement). Spectra were collected at sampling intervals of $1.4 \mathrm{~nm}$ at 350 to $1,000 \mathrm{~nm}$ and $2 \mathrm{~nm}$ at 1,000 to $2,500 \mathrm{~nm}$ with the following full width at half maximum (FWHM) spectral resolutions: $5.6 \mathrm{~nm}$ at $\sim 435 \mathrm{~nm}, 3.5 \mathrm{~nm}$ at $\sim 700 \mathrm{~nm}$, and $4.9 \mathrm{~nm}$ at $\sim 910 \mathrm{~nm}$ at VNIR wavelengths (determined by measurement of an Hr-Ar lamp at the Natural Environment Research Council Field Spectroscopy Facility) and 11 nm at SWIR wavelengths (determined by the U.S. Geological Survey Spectroscopy Lab using the same class of ASD; http:// speclab.cr.usgs.gov/spectral.lib06/ds231/index.html). Absolute reflectance values were calculated by calibrating each batch of $\sim 20$ repeat measurements against a Spectralon white reference panel that was also measured at the end of each batch to monitor for instrumental drift. Individual measurements sample an ellipse approximately $10 \times 5 \mathrm{~mm}$ in size.

In order to maximize the quality of VIS-SWIR spectra, $\sim 50-\times 50-\mathrm{mm}$ flat surfaces were cut into the samples and polished coarsely to ensure good optical coupling with the ASD contact probe. The effect of compositional heterogeneity on sample spectra was mitigated by averaging over up to 94 evenly spaced repeat measurements taken from across sample surfaces. The typical $1 \sigma$ precision of individual spectra estimated from repeat measurements of an identical field of view is $<0.5 \%$ relative.

\section{Thermal IR thermal emission spectroscopy}

Thermal IR $(\lambda=8-15 \mu \mathrm{m})$ reflectance spectra of 20 samples were calculated from thermal emission spectra measured using a Midac M4410-S Fourier transform infrared field spectrometer equipped with a ZnSe beam-splitter and Stirling pump-cooled MCT detector at the Natural Environment Research Council Field Spectroscopy Facility, using Kirchhoff's law (Nicodemus, 1965): $\varepsilon=1-r$, where $r=$ reflectance and $\varepsilon=$ emissivity. Although the full spectral range of the 
spectrometer is 1.5 to $15.4 \mu \mathrm{m}\left(7,800-650 \mathrm{~cm}^{-1}\right)$, reflectance was only calculated at thermal IR wavelengths where analytical noise was sufficiently low to resolve emissivity values (8-15 $\mu \mathrm{m})$. Spectra were collected with a spectral resolution of 0.5 $\mathrm{cm}^{-1}$ and at a constant working distance of $75 \mathrm{~mm}$. This working distance results in a field of view of $\sim 40 \times 40 \mathrm{~mm}$, which is approximately equivalent to sample area integrated over multiple ASD measurements.

Sample radiance was determined using a two-temperature black body calibration method where black body temperatures of $45^{\circ}$ and $80^{\circ} \mathrm{C}$ were selected to bracket sample temperatures of $50^{\circ}$ to $70^{\circ} \mathrm{C}$ (e.g., Hook and Kahle, 1996; Korb et al., 1996). In order to overcome the substantial errors in thermal emission spectra introduced from uncertainties in measuring the temperature of samples, calculations were performed using temperatures determined from an algorithm that assumes a maximum emissivity of 0.98 within the 8- to $13-\mu \mathrm{m}$ window (Kahle and Alley, 1992). Emissivity was subsequently calculated from radiance by subtracting downwelling radiance (DWR) measurements collected using an InfraGold ${ }^{\circledR}$ plate $(\varepsilon<0.06)$. Thermal IR spectra presented in this contribution are thus subject to a number of assumptions and should only be considered as guideline values. The typical $1 \sigma$ precision of thermal emission spectra within 8 to $15 \mu \mathrm{m}$ estimated from repeat measurements is $2 \%$ relative.

\section{Geologic Contexts and Mineral Assemblages}

\section{Bayan Obo (China), Mountain Pass (United States), and Mount Weld (Australia)}

The Bayan Obo Fe-REE-Nb deposit in China, which currently dominates global REE supply (Wall, 2014), experienced a convoluted and potentially unique petrogenetic history that has been reviewed comprehensively by Smith et al. (2014). Major REE minerals include bastnäsite-(Ce), monazite-(Ce), parisite-(Ce), and huanghoite-(Ce) (Fig. 3A). Apatite is also present but contains significantly lower concentrations of REEs than the REE minerals (Campbell and Henderson, 1997). The samples used in our study were described in detail by Smith et al. (2000), and span four paragenetic groups: Disseminated Monazite stage, Banded Ore, Fluorite stage, and Barite stage (Table 1).

Prior to the onset of mining at Bayan Obo in China, the Sulphide Queen carbonatite at Mountain Pass in the United States was the world's largest light (L)REE source (Castor, 2008). Active mining restarted in 2010. Mountain Pass is particularly noteworthy for the great abundance of bastnäsite(Ce) (Table 1; Fig. 3B; Olson et al., 1954), which is thought, almost uniquely, to have crystallized directly from a carbonatite melt (Mariano, 1989).

Mount Weld in Western Australia started processing ore in 2011 and is one of the main LREE mines outside of China. Lottermoser (1990) provided a detailed petrologic description of this highly weathered complex. The primary REE-bearing minerals present in the ankeritic carbonatite investigated in this study are apatite, monazite-(Ce) and synchysite-(Ce) (Table 1).

\section{East and South Africa}

Kangankunde, Tundulu, Songwe, and Chilwa Island are located within the Chilwa alkaline province of Malawi (Garson,

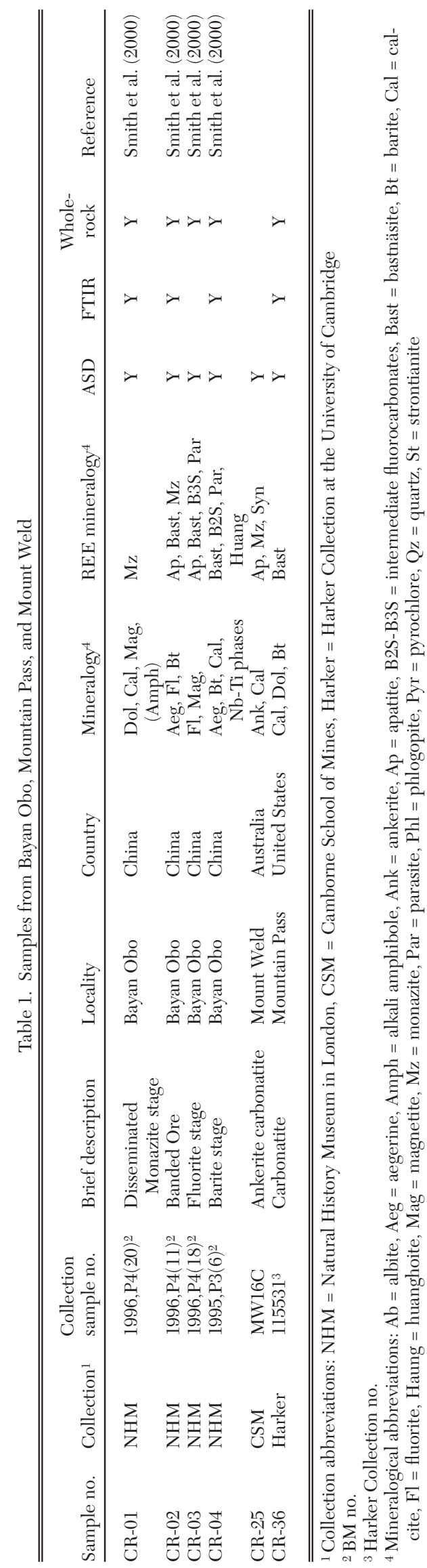




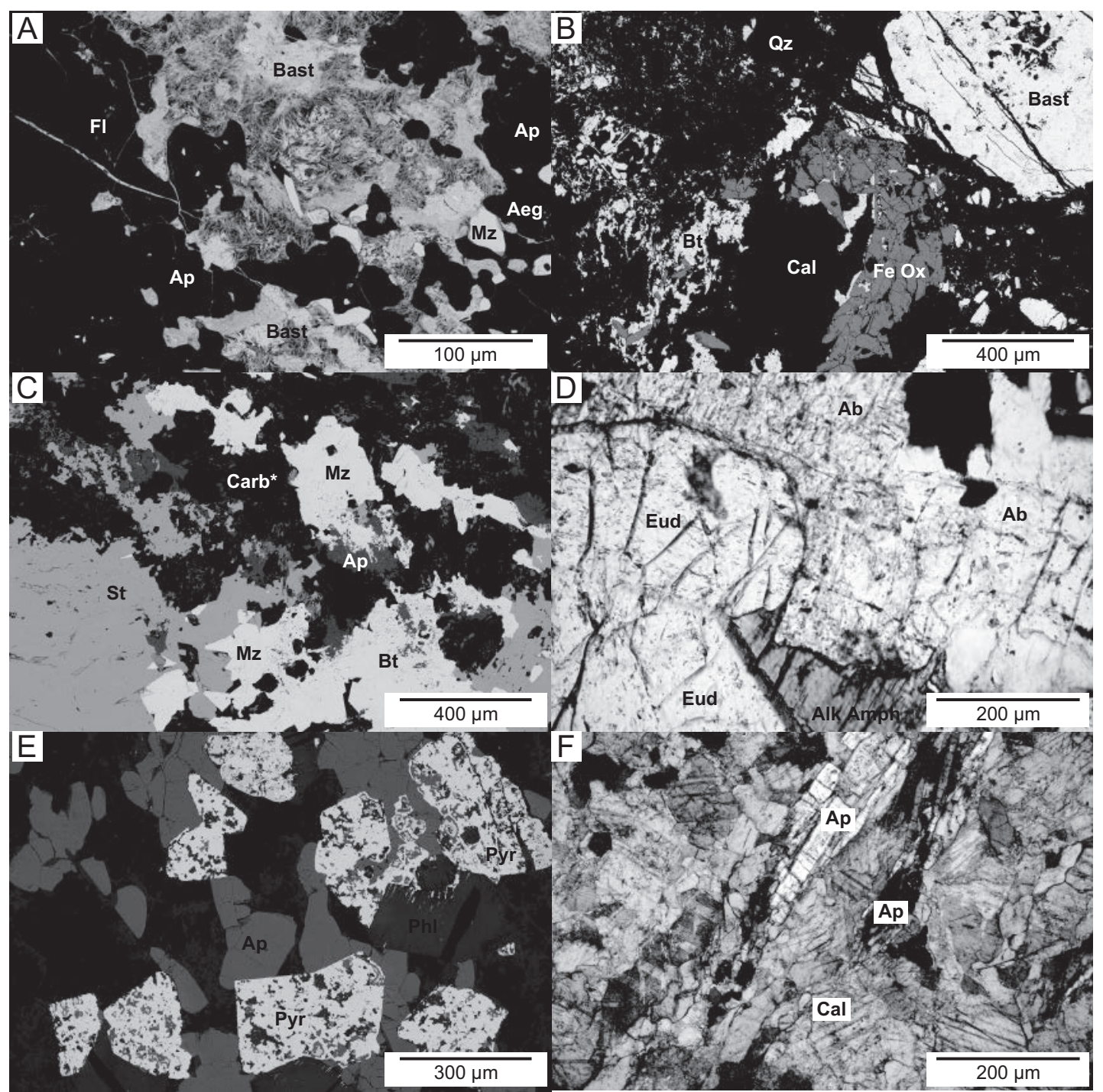

Fig. 3. Backscattered electron (BSE) and optical photomicrographs of key REE-rich samples. A. BSE image of the Banded Ore from Bayan Obo, China (CR-02). B. BSE image of a sample from Mountain Pass, United States (CR-36). C. BSE image of a sample from Kangankunde, Malawi (CR-16). D. Photomicrograph with plane polars of kakortokite from Ilímaussaq, Greenland (CR-46). E. BSE image of a sample from St. Honoré, Canada (CR-15). F. Photomicrograph with crossed polars of Fen, Norway (CR-17). Mineral labels are as follows: $\mathrm{Ab}=$ albite, Aeg = aegirine, Alk Amph = alkali amphibole, Ap = apatite, Bast $=$ bastnäsite, $\mathrm{Bt}=$ barite, $\mathrm{Carb}=$ calcite-dolomite-ankerite mix, $\mathrm{Carb}^{*}=$ calcite-dolomite-ankerite-Mn carbonate, $\mathrm{Cal}=$ calcite, $\mathrm{Eud}=$ eudialyte, $\mathrm{Fe} \mathrm{Ox}=\mathrm{Fe}$ oxides, $\mathrm{Fl}=$ fluorite, $\mathrm{Mz}=$ monazite, $\mathrm{Phl}=$ phlogopite, $\mathrm{Pyr}=$ pyrochlore, $\mathrm{Qz}=$ quartz, and $\mathrm{St}=$ strontianite.

1965). While igneous rocks from these complexes are highly variable, Fe-rich compositions dominated by ankerite and magnetite are the most common (Table 2). Wall and Mariano (1996) provided a detailed discussion of REE mineralization in Kangankunde, where REE mineralogy is dominated by monazite-(Ce) and bastnäsite-(Ce) (Fig. 3C). The REE fluorcarbonate synchysite-(Ce) is present in samples from Tundulu and Songwe, with florencite and apatite also hosting minor REE components (Broom-Fendley et al., 2016). Apatite and pyrochlore are the major REE-bearing phases at Chilwa Island, though bastnäsite and florencite can also be present (Simonetti and Bell, 1994).

Tororo and Sukulu in Uganda lie within the same dominantly calciocarbonatitic igneous complex (Williams, 1952;
McCormick and Le Bas, 1996). Apatite is the major REE host in these centers (Table 2) and has been the subject of fluid inclusion studies interrogating the origins of carbonaterich liquids (Rankin, 1977; Ting et al., 1994). The REE-poor Fort Portal extrusive carbonatite, also located in Uganda, is described in detail by Eby et al. (2009).

Although the Panda Hill complex of Tanzania is a largely calciocarbonatitic in nature, magnesiocarbonatite and ferrocarbonatite are also present (Basu and Mayila, 1986). REEs are primarily hosted in apatite and pyrochlore (Table 2 ), with the latter being sufficiently abundant to represent a potential $\mathrm{Nb}$ resource (Mitchell, 2015).

The Proterozoic Phalaborwa (Palabora) complex of South Africa is unusually $\mathrm{Cu}$ rich (Eriksson, 1989), with apatite 


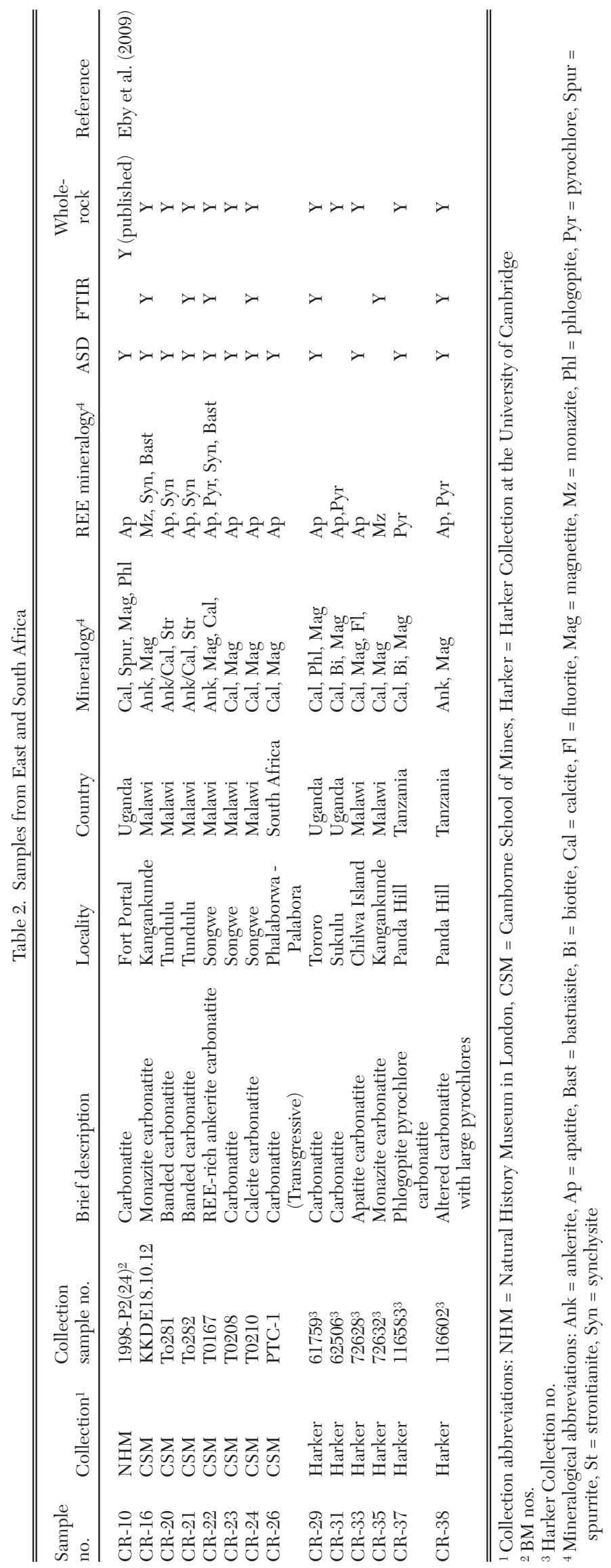

crystals from the central transgressive carbonatite containing appreciable quantities of REEs (Ce $\sim 3,000$ ppm; Dawson and Hinton, 2003).

\section{Greenland and Canada}

The Jurassic Tikiusaaq and Qeqertaasaq carbonatites of west Greenland are likely to be associated with the incipient rifting of the Labrador sea (Tappe et al., 2007). While exploration of these complexes is ongoing, Tappe et al. (2009) discussed the petrology of Tikiusaaq in relationship to possible kimberlitecarbonatite associations. Ancylite-(Ce) is the dominant REE phase in these carbonatites alongside parisite-(Ce), though small quantities of the HREE mineral churchite-(Y) have been reported from Tikiusaaq (Table 3).

Both the Motzfeldt and Ilímaussaq alkaline igneous intrusions are located within the Proterozoic (1300-1140 Ma) Gardar province of southwest Greenland. Jones and Larsen (1985) provided a geochemical framework for the Motzfeldt intrusion as well as documenting the occurrence of REE-rich phases such as apatite and eudialyte. McCreath et al. (2013) discussed the chemistry of REE-bearing pyrochlore minerals from within the Peralkaline Microsyenite Suite of the Motzfeldt $\$ \varnothing$ formation that have been analyzed in this study (Table 3). Given the petrologic heterogeneity of the dominantly peralkaline Ilímaussaq intrusion (Ferguson, 1970; Bailey et al., 2001), we have only investigated the properties of a eudialyte-rich kakortokite (albite + eudialyte + amphibole; Fig. 3D) that may represent a future REE resource (Ferguson, 1970; Wall, 2014).

Oka and St. Honoré are located within the Ontario carbonatite province of Ontario and western Quebec (Erdosh, 1979). Apatite and pyrochlore represent the main REE-bearing phases in these complexes (Table 3; Fig. 3E). St. Honoré is the largest current source of $\mathrm{Nb}$ outside of Brazil (Mitchell, 2015).

\section{Scandinavia and Germany}

The Sokli complex of Finland lies at the western limit of the Kola alkaline province and has been described in detail by Vartiainen and Paarma (1979). Apatite is present at high modal proportions within carbonatite and phoscorite portions of the complex and is the major REE hosting mineral (Table 4). REEs are particularly abundant in weathered apatite-rich material at the surface.

Apatite is also the main host of REEs in samples from Fen in Norway and Kaiserstuhl in Germany (Andersen, 1988; Hornig-Kjarsgaard, 1998; Table 4; Fig. 3F), though accumulations of monazite within the Fen complex have been mapped recently by Boesche et al. (2015).

\section{Other locations}

The extrusive carbonatite samples from Uyaynah in the United Arab Emirates were collected from a tectonic window through the Semail Ophiolite Complex and are described in detail by Woolley et al. (1991). REEs are primarily hosted in allanite and apatite at Uyaynah (Table 5).

Huang et al. (1995) provided a geochemical overview of the Jacupiranga carbonatite of Brazil that is especially rich in apatite (Table 5), with further whole-rock analyses provided by Hornig-Kjarsgaard (1998). 


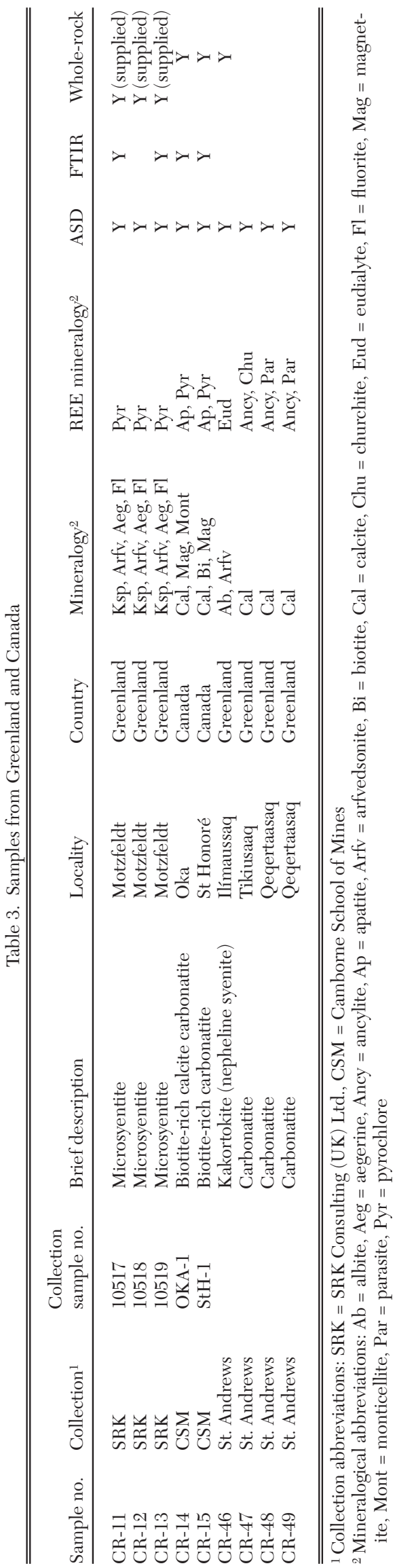

\section{Whole-Rock Geochemistry}

\section{Major element compositions}

With the exception of lavas from Uyaynah and Fort Portal (CR-05-CR-10), all samples in this study are intrusive rocks. Most samples are carbonate rich and have compositions that can be summarized using the ternary classification diagram of Woolley and Kempe (1989; Fig. 4). Full major element compositions are provided in the supplementary material. While most carbonatites form a single array from calciocarbonatite to ferrocarbonatite compositions, three compositions lie toward the center of the diagram: CR-15 from St. Honoré lies on the tie line between magnesio- and ferrocarbonatites but is strongly affected by magnetite accumulation; CR-16 from Kangankunde lies within the ferrocarbonatite field; and CR-33 from Chilwa Island lies within the magnesiocarbonatite field. Despite its high REE content, CR-36 from Mountain Pass is one of the purest calciocarbonatites investigated.

Samples CR-01 to CR-04 from Bayan Obo cannot be readily classified based on their major element chemistry. Nevertheless, the high $\mathrm{MgO}$ content of CR-01 from the Disseminated Monazite is consistent with its original petrogenesis as a dolomitic marble (Smith et al., 2015). All samples from Bayan Obo also have appreciable $\mathrm{Fe}_{2} \mathrm{O}_{3}$ contents reflecting the high degree of $\mathrm{Fe}$ mineralization across the complex.

Although no major element data are available for samples CR-11 to CR-13 from the silicate Motzfeldt intrusion, Bradshaw (1988) reported peralkaline syenite compositions (atomic $(\mathrm{Na}+\mathrm{K}) / \mathrm{Al})>1$ ) from the same rock unit, the Peralkaline Microsyenite Formation. Sample CR-46, a kakortokite from the Ilímaussaq intrusion, is rich in alkalis and can be classified as a nepheline syenite (Le Bas et al., 1986). A low total of 90.1 wt \% reflects the sample's high $\mathrm{Zr}$, Nb, REE, F, and $\mathrm{Cl}$ contents. When $\mathrm{Zr}, \mathrm{Nb}$, and REEs are recalculated as oxides, a total of $103.0 \mathrm{wt} \%$ is obtained.

REE- and Nb-poor samples (such as CR-33 and CR-42 from Chilwa Island and Sokli, respectively) have major element

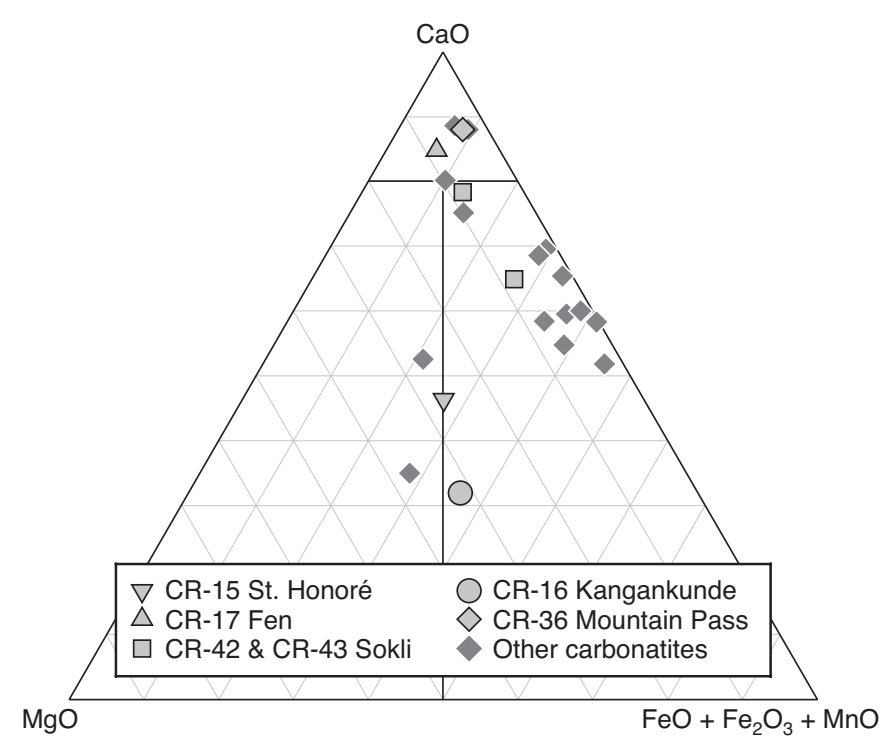

Fig. 4. Classification of carbonatites following the scheme of Woolley and Kempe (1989). 
Table 4. Samples from Scandinavia and Germany

\begin{tabular}{|c|c|c|c|c|c|c|c|c|c|c|}
\hline Sample no. & Collection $^{1}$ & $\begin{array}{l}\text { Collection } \\
\text { sample no. }\end{array}$ & Brief description & Locality & Country & Mineralogy $y^{3}$ & $\begin{array}{c}\text { REE } \\
\text { mineralogy }\end{array}$ & ASD & FTIR & Whole-rock \\
\hline CR-17 & CSM & Fen202/76 & Calcite carbonatite & Fen & Norway & $\mathrm{Cal}, \mathrm{Bi}$ & Ap & $\mathrm{Y}$ & $\mathrm{Y}$ & $\mathrm{Y}$ \\
\hline CR-19 & $\mathrm{CSM}$ & Intrusive & Calcite carbonatite & Kaiserstuhl & Germany & Cal, Mag, Ol & Ap & $\mathrm{Y}$ & & $\mathrm{Y}$ \\
\hline CR-42 & Harker & $117676^{2}$ & Phyrochlore sovite & Sokli & Finland & Cal, Mag & Ap & $\mathrm{Y}$ & $\mathrm{Y}$ & $\mathrm{Y}$ \\
\hline CR-43 & Harker & $117677^{2}$ & Coarse sovite & Sokli & Finland & Cal, Mag & Ap & $\mathrm{Y}$ & & $\mathrm{Y}$ \\
\hline
\end{tabular}

${ }^{1}$ Collection abbreviations: CSM = Camborne School of Mines, Harker = Harker Collection at the University of Cambridge

${ }^{2}$ Harker Collection no.

${ }^{3}$ Mineralogical abbreviations: $\mathrm{Ap}=$ apatite, $\mathrm{Bi}=$ biotite, $\mathrm{Cal}=$ calcite, $\mathrm{Fl}=$ fluorite, $\mathrm{Mag}=$ magnetite $. \mathrm{Ol}=\mathrm{olivine}$

(including LOI) totals that approach $100 \%$. However, a number of samples initially appear to have unacceptably low totals ( 50 wt \% including LOI). Although analytical accuracy and precision are affected by the extreme and variable compositions of these samples, such low totals result primarily from the high concentration of elements that typically occur in trace quantities in most other igneous rocks. If $\mathrm{Ce}, \mathrm{La}, \mathrm{Nb}$, $\mathrm{Nd}$, Sr, $\mathrm{Y}$, and $\mathrm{Zr}$ are recalculated as oxides, then most samples have totals that lie between 97 and 103 wt \%. Remaining exceptions include F-rich samples, such as fluorite-bearing CR-03 from Bayan Obo, and Ba-rich samples, such as CR-02 from Bayan Obo and CR-36 from Mountain Pass. However, recalculating $\mathrm{Ba}$ as $\mathrm{BaO}$ results in the overestimation of totals (supplementary material), indicating that Ba was poorly quantified in these samples.

\section{REE contents}

Sample REE systematics are summarized in Figure 5 and Nd contents are provided in Table 6. Full trace element compositions are provided in the supplementary material. Trace element concentrations in many samples lie above the range of XRF calibration possible with the standards available $(\sim 2,000 \mathrm{ppm}$ for most elements and $\sim 2,800 \mathrm{ppm}$ in the case of $\mathrm{Nd}$ ), and the resulting analyses must be treated as semiquantitative. Trace element quantification by XRF is further hampered by complex $\mathrm{X}$-ray interferences resulting from extreme and variable matrix effects. While achieving full quantification is beyond the resources of this exploratory study, relative errors in whole-rock trace element contents are unlikely to exceed $20 \%$ except in the case of Ba. Encouragingly, REE contents of samples CR-02 and CR-36 are of the same order as values reported from Bayan Obo and Mountain Pass ores by Smith et al. (2014) and Castor (2008), respectively.

Measured REE abundances vary by more than three orders of magnitude, with $\mathrm{Nd}$ contents varying from $~ 140$ to $443,300 \mathrm{ppm}$ (Fig. 5). Most samples show enrichments in LREEs, with chondrite-normalized concentrations ordered as follows $\mathrm{La}>\mathrm{Ce}>\mathrm{Nd}>\mathrm{Y}$. The highest $\mathrm{Nd}$ concentrations are found in CR-02 from Bayan Obo ( 38,600 ppm), CR-16 from Kangankunde ( 43,300 ppm) and CR-36 from Mountain Pass ( $\sim 30,800 \mathrm{ppm})$. Thin sections of these samples show evidence of extensive REE mineralization: CR-02 contains abundant fibrous bastnäsite-(Ce) as well as monazite-(Ce) (Fig. 3A); CR-16 contains abundant monazite-(Ce) (Fig. 3C); and CR-36 contains euhedral bastnäsite-(Ce) (Fig. 3B). Apatite- and pyrochlore-bearing samples have lower Nd contents $(<1,000 \mathrm{ppm})$, with the following exceptions: CR-13 from Motzfeldt, CR-21 from Tundulu, and CR-22-24 from
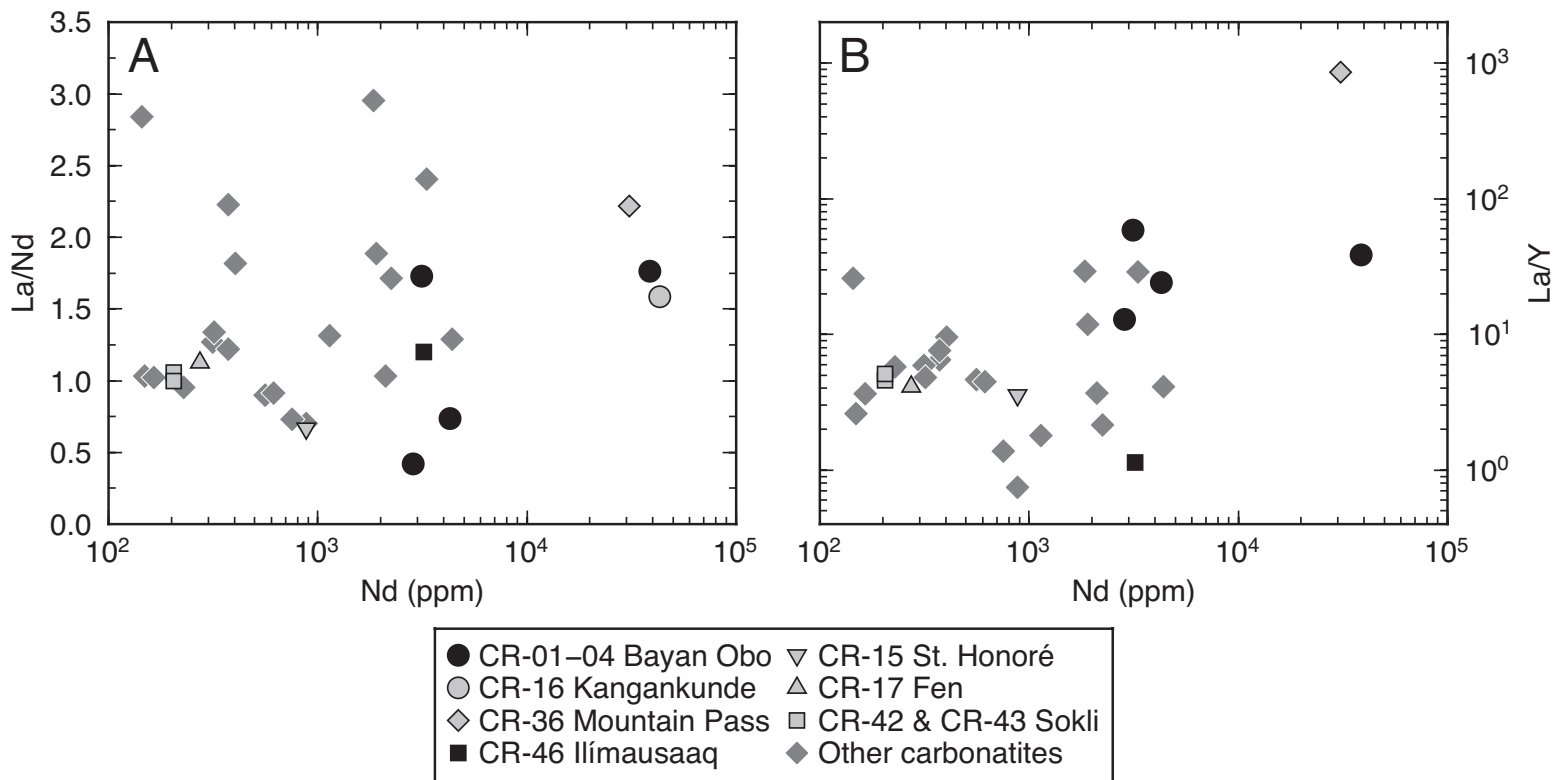

Fig. 5. Plots summarizing sample REE systematics. A. La/Nd vs. Nd. B. La/Y vs. Nd. 
Songwe. Eudialyte-bearing CR-46 from Ilímaussaq contains $\sim 3,200$ ppm Nd (Fig. 3F).

\section{Reflectance Spectra}

VNIR-SWIR reflectance spectra

The diverse nature of reflectance spectra collected in this study reflects the substantial geochemical, mineralogical, and textural variability within our sample suite. Nevertheless, it is possible to divide the sample suite into six groups based on the minerals that dominate each spectrum. All measured spectra are provided in the supplementary material.

Magnetite-dominated spectra: Samples from the Bayan Obo Fluorite stage (CR-03), Uyaynah (CR-05-CR-09), and Fort Portal (CR-10) have low absolute reflectance $(\leq 15 \%)$ at VNIR-SWIR wavelengths (Fig. 6) that reflect abundant magnetite in the case of the Bayan Obo sample and disseminated, fine-grained magnetite in the cases of the Uyaynah and Fort Portal samples (Smith et al., 1985; Clark, 1995). A number of samples show weak absorptions at $\sim 2,300 \mathrm{~nm}$ that indicate the presence of $\mathrm{CO}_{3}$ groups. Reflectance maxima at 500 to $700 \mathrm{~nm}$ in samples CR-08 and CR-10 from Uyaynah and Fort Portal are indicative of Fe-rich carbonate (Gaffey, 1985; Woolley et al., 1991). Weak absorption features at 744 and $~ 802 \mathrm{~nm}$ in spectra from the Bayan Obo Fluorite stage (CR-03) are consistent with the presence of bastnäsite-(Ce) and parisite-(Ce)-hosted $\mathrm{Nd}$, but are significantly damped by magnetite (Figs. 1, A1A). Although CR-15 from St. Honoré has a $\mathrm{CO}_{3}$ absorption feature centered at $\sim 2,300 \mathrm{~nm}$ corresponding to the presence of calcite (Gaffey, 1985), other spectral features are difficult to resolve because the low overall reflectance of this pyrochlore-rich sample (Fig. 3E).

Fe-poor carbonate-dominated spectra: Samples from Oka (CR-14), Jacupiranga (CR-18), Mountain Pass (CR-36), Sokli (CR-42, CR-43), and Qeqertaasaq (CR-48, CR-49) exhibit largely flat spectra of generally high absolute reflectance (up to $\sim 55 \%$ ) onto which narrow absorption features are

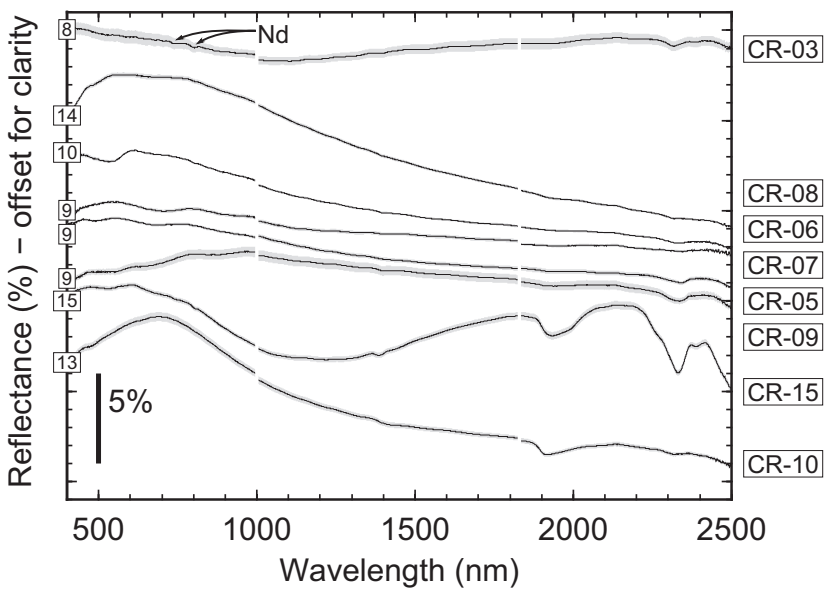

Fig. 6. Mean VNIR-SWIR spectra of samples dominated by magnetite collected using an ASD spectroradiometer under laboratory conditions (CR-03, $n=37$; CR-05, $n=43$; CR-06, $n=34$; CR-07, $n=9$; CR-08, $n=53$; CR-09, $n=19$; CR-10, $n=20$; CR-15, $n=75$ ). Gray envelopes show the standard errors of the mean spectra. Absolute reflectance values are shown at $400 \mathrm{~nm}$. Sample locations and rock types for spectra can be found in Tables 1-5. 
IMAGING CARBONATITE-HOSTED REE DEPOSITS USING REMOTE SENSING

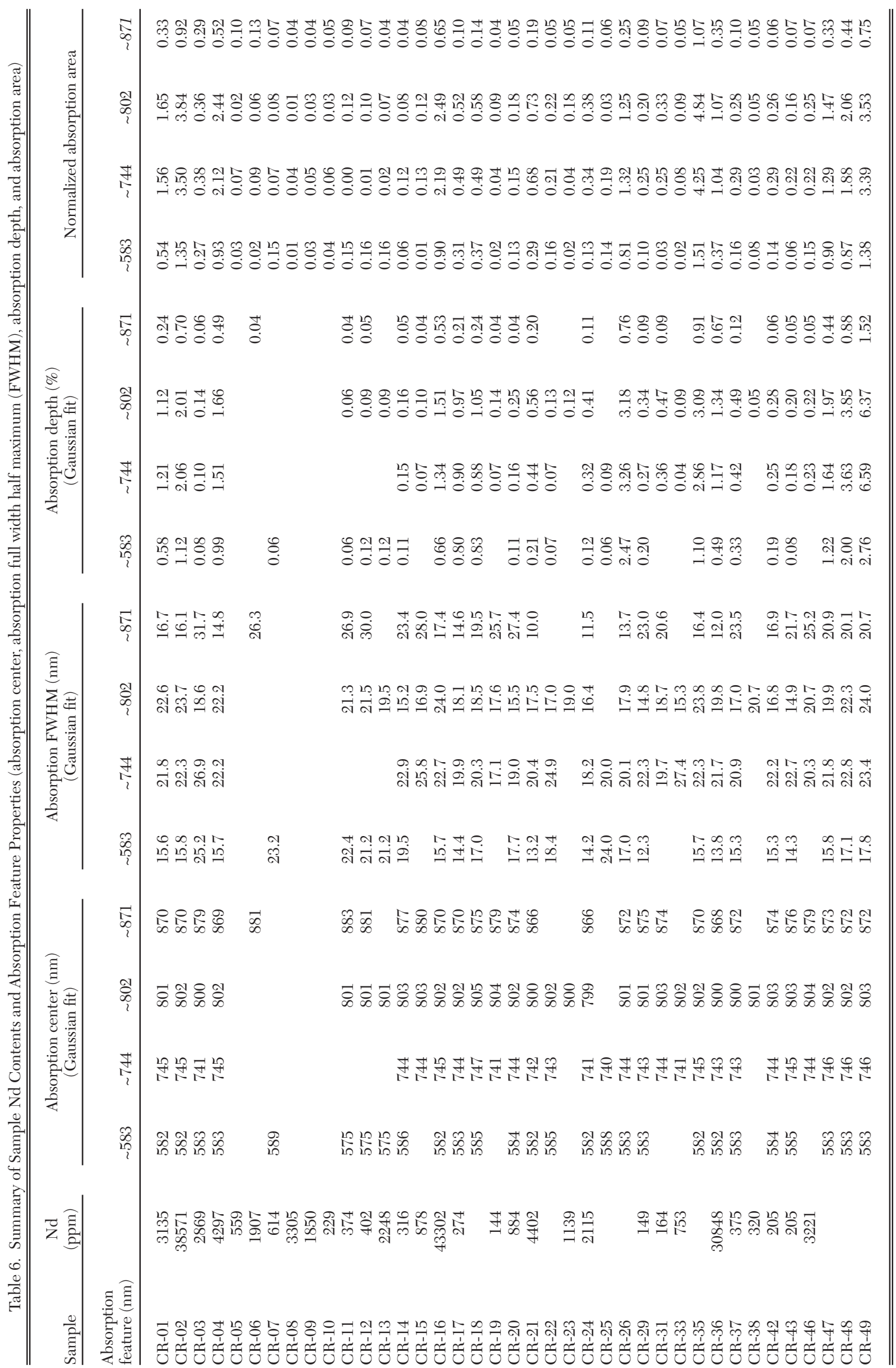


superimposed (Fig. 7). Deep absorption features at $\sim 2,300$ $\mathrm{nm}$ without a broad absorption feature centered on $\sim 1,200$ $\mathrm{nm}$ are characteristic of Fe-poor calcite and dolomite (Figs. 1, A1B, A2A; Gaffey, 1985). Broad absorption features at $\sim 1,900 \mathrm{~nm}$ related to $\mathrm{H}_{2} \mathrm{O}$ may represent either hydrated minerals (e.g., ancylite-(Ce)), fluid inclusions, or adsorbed water (Gaffey, 1985; Rowan et al., 1986). However, assigning $\mathrm{H}_{2} \mathrm{O}$ (and $\mathrm{OH}^{-}$) features to specific minerals is of limited use in a remote sensing context: this information is lost in air- and spaceborne datasets because of atmospheric $\mathrm{H}_{2} \mathrm{O}$ (see later). Sharp drops in reflectance below $500 \mathrm{~nm}$ in most samples probably reflect the presence of $\mathrm{Mn}$ within calcite (Gaffey, 1985). The steep drop in reflectance below $600 \mathrm{~nm}$ in the Mountain Pass sample (CR-36) is consistent with the presence of barite (Figs. A1B, A2B; Clark et al., 2007; Castor, 2008).

Narrow absorption features at $\sim 583, \sim 744, \sim 802$, and $\sim 871 \mathrm{~nm}$ in samples from Jacupiranga (CR-18), Mountain Pass (CR-36), and Qeqertaasaq (CR-48, CR-49) can be attributed to Nd hosted primarily within apatite, bastnäsite-(Ce) and ancylite-(Ce), respectively (Rowan et al., 1986). Minor absorption features at $\sim 583, \sim 744$, and $\sim 802 \mathrm{~nm}$ in samples from Oka (CR-14) and Sokli (CR-42, CR-43) correspond to the presence of $\mathrm{Nd}$ at lower concentrations; the high overall reflectance of these samples makes these small spectral features resolvable. Absorption features associated with other REEs are difficult to assign unambiguously; while complex absorption features at $\sim 1,550$ and $\sim 1,970 \mathrm{~nm}$ are likely to

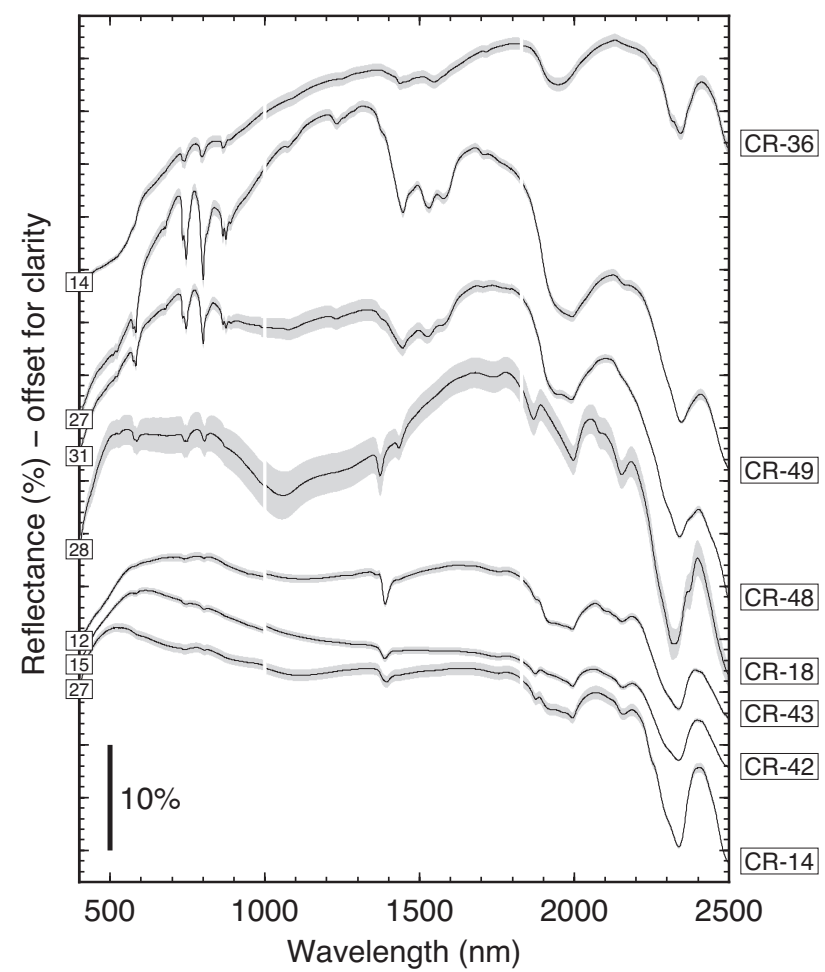

Fig. 7. Mean VNIR-SWIR spectra of samples dominated by Fe-poor carbonates collected using an ASD spectroradiometer under laboratory conditions (CR-14, $n=71$; CR-18, $n=17$; CR-36, $n=68$; CR-42, $n=34$; CR-43, $n=39$; CR-48, $n=63$; CR-49, $n=57$ ). Gray envelopes show the standard errors of the mean spectra. Absolute reflectance values are shown at $400 \mathrm{~nm}$. Sample locations and rock types for spectra can be found in Tables 1-5. have Pr and Sm components, they also encompass $\mathrm{OH}^{-}, \mathrm{H}_{2} \mathrm{O}$, and Nd features (Turner et al., 2014). Furthermore, contributions from HREEs are difficult to assess because currently published spectral libraries include only LREE-rich minerals (e.g., Clark et al., 2007; Turner et al., 2014).

$\mathrm{Fe}$-rich carbonate-dominated spectra: Samples from the Bayan Obo Disseminated Monazite stage (CR-01), Fen (CR17), Mount Weld (CR-25), Phalaborwa (CR-26), Tororo (CR29), Sukulu (CR-31), and Panda Hill (CR-37) have distinctive "M"-shaped reflectance spectra (Fig. 8). Broad absorption features centered at $\sim 1,200 \mathrm{~nm}$ are consistent with Fe-bearing calcite, dolomite, and ankerite (Figs. 1, A1C; Gaffey, 1985; Mars and Rowan, 2011). $\mathrm{CO}_{3}$ absorption features centered at $\sim 2,300 \mathrm{~nm}$ are prominent in all spectra. Additional $\mathrm{CO}_{3}$ absorptions at $\sim 1,880, \sim 2,000$, and $\sim 2,160 \mathrm{~nm}$ are visible in most samples, apart from those from Bayan Obo. $\mathrm{H}_{2} \mathrm{O}$ absorption features are also present, and $\mathrm{OH}^{-}$features at $\sim 1,400 \mathrm{~nm}$ are clear in samples from Tororo (CR-29) and Panda Hill (CR-37).

The strongest $\mathrm{Nd}$ absorption features within this group occur in apatite-bearing samples from Fen (CR-17) and Phalaborwa (CR-26), and monazite-(Ce)-bearing samples from the Bayan Obo Disseminated Monazite stage (CR-01). Apatite- and pyrochlore-bearing samples from Tororo (CR-29), Sukulu (CR-31), and Panda Hill (CR-37) show only weak Nd absorptions despite having a higher overall reflectance than CR-01, which is consistent with the low REE content of minerals in these samples (Fig. AlC). Furthermore, no features

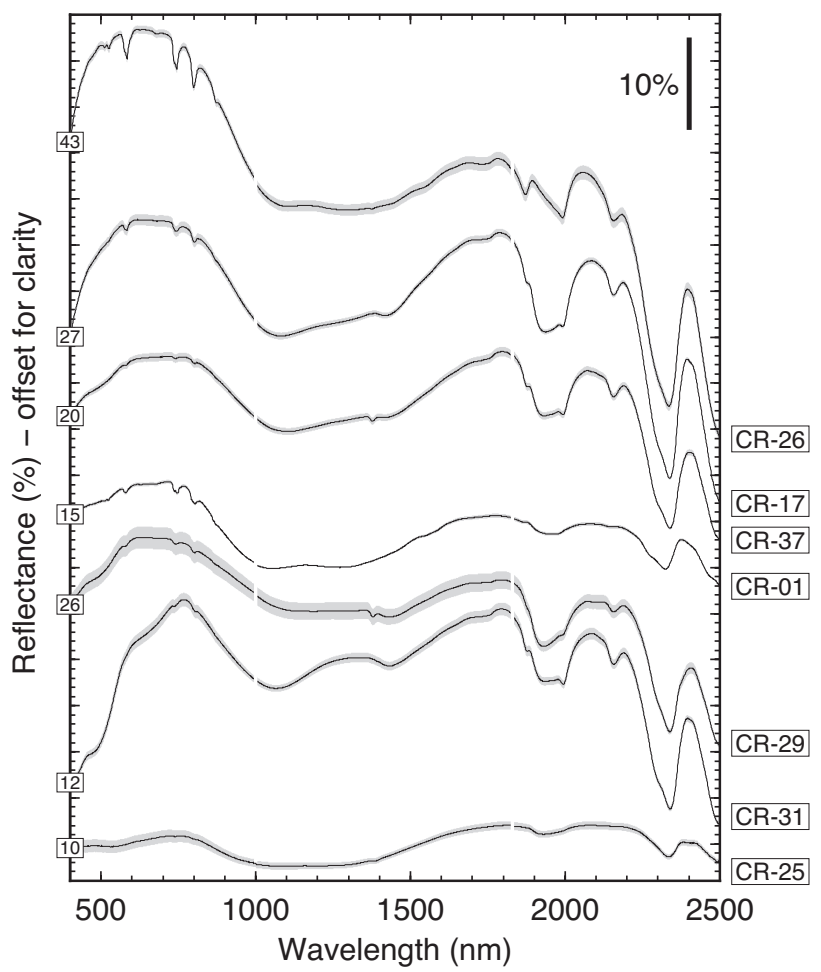

Fig. 8. Mean VNIR-SWIR spectra of samples dominated by Fe-rich carbonates collected using an ASD spectroradiometer under laboratory conditions (CR-01, $n=94$; CR-17, $n=43$; CR-25, $n=20$; CR-26, $n=15$; CR-29, $n=39$; CR-31, $n=44$; CR-37, $n=52$ ). Gray envelopes show the standard errors of the mean spectra. Absolute reflectance values are shown at $400 \mathrm{~nm}$. Sample locations and rock types for spectra can be found in Tables 1-5. 
associated with Pr or Sm can be identified in these spectra. Sample CR-25 has a low overall reflectance, which impedes the identification REE absorptions.

Fe oxide-carbonate mixed spectra: Samples from Kangankunde (CR-16, CR-35), Kaiserstuhl (CR-19), Songwe (CR-22-CR-24), Chilwa Island (CR-33), Panda Hill (CR-38), and Tikiusaaq (CR-47) have sloping spectra with reflectance values that generally increase from 400 to $1,800 \mathrm{~nm}$ (Fig. 9). Absorptions at $\sim 2,300 \mathrm{~nm}$ reflect the presence of $\mathrm{CO}_{3}$ in all of these samples, though magnetite is also an important constituent of many of these samples (Figs. 1, A1D). Broad absorption features centered at 950 to $1,000 \mathrm{~nm}$ present to varying degrees within this group of spectra are characteristic of goethite that probably formed by the alteration of primary magnetite or by exsolution from $\mathrm{Fe}$-rich carbonates (Fig. A2C; Clark et al., 2007).

Strong $\mathrm{Nd}, \mathrm{Pr}$, and $\mathrm{Sm}$ absorption features in samples from Kangankunde (CR-16, CR-35) can be attributed to the high modal abundance of moderately coarse monazite-(Ce) $(\sim 500 \mu \mathrm{m})$ in these samples (Figs. 1, 3C), though smaller quantities of bastnäsite-(Ce) and other REE-rich phases such strontianite may also contribute (Fig. A1D; Wall and Mariano, 1996). Prominent Nd absorption features in CR-47 from Tikiusaaq can be accounted for by the presence of significant quantities of ancylite-(Ce). Unfortunately, no published spectra of ancylite-(Ce) that would enable us to confirm this association are known to the authors.

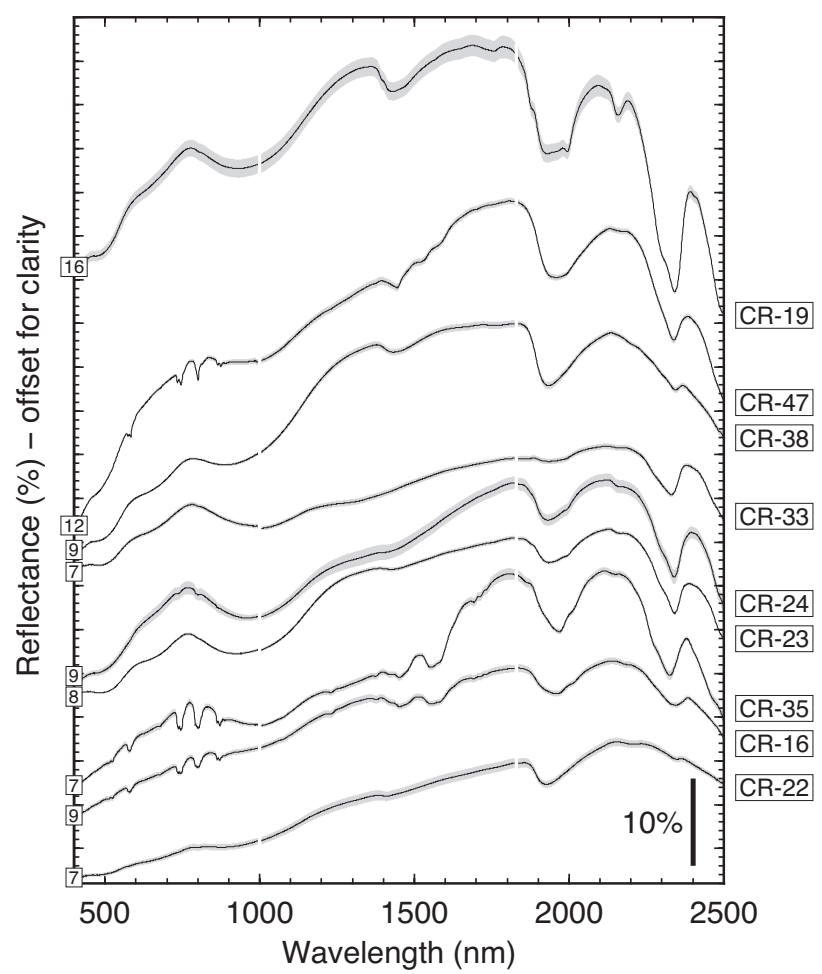

Fig. 9. Mean VNIR-SWIR spectra of samples dominated by mixtures of $\mathrm{Fe}$ oxides and carbonates collected using an ASD spectroradiometer under laboratory conditions (CR-16, $n=96$; CR-19, $n=41$; CR-22, $n=41$; CR-23, $n$ $=38$; CR-24, $n=48$; CR-35, $n=54$; CR-38, $n=39$; CR-47, $n=49$ ). Gray envelopes show the standard errors of the mean spectra. Absolute reflectance values are shown at $400 \mathrm{~nm}$. Sample locations and rock types for spectra can be found in Tables 1-5.
REE-dominated spectra: Samples from the Bayan Obo Banded Ore (CR-02) and Barite stage (CR-04) have largely flat reflectance spectra, onto which numerous complex absorption features are superimposed (Fig. 10). These samples contain abundant colorless aegirine with largely featureless reflectance spectra at 500 to $800 \mathrm{~nm}$ (Ribeiro Da Costa et al., 2013). Most prominent absorptions in these spectra from Bayan Obo can be attributed to $\mathrm{Pr}, \mathrm{Sm}$, and Nd (Fig. 1). In addition to bastnäsite-(Ce), monazite-(Ce) and parisite(Ce) occur in the Banded Ore (Fig. AlE). Huanghoite-(Ce) is present also alongside other REE fluorcarbonates in the Barite stage (Smith et al., 2000). The depth of REE absorptions are possibly enhanced by the unusually coarse grain size of REE minerals in these samples ( 1 mm; Smith et al., 2014).

Alkaline igneous rock spectra: Samples from Motzfeldt (CR-11-CR-13, CR-45) and Ilímaussaq (CR-46) are variably altered silicate rocks and contain no carbonate (Fig. 10). All four Motzfeldt samples have a similar spectra that are best attributed to the presence of hematite (Fig. A2D; Clark et al., 2007): reflectance increases steeply between 600 and $700 \mathrm{~nm}$ before decreasing across smooth absorption features centered at $\sim 860 \mathrm{~nm}$. Absorption features at $\sim 1,400$ and $\sim 1,900 \mathrm{~nm}$ in samples from Motzfeldt probably correspond to the presence of $\mathrm{OH}^{-}$-bearing alteration materials rather than primary hydrous minerals.

Sample CR-46 from Ilímaussaq is significantly less altered than samples from Motzfeldt and is composed of albite, eudialyte, and interstitial alkali amphibole. Given that albite has a largely featureless reflectance spectrum at VNIR-SWIR wavelengths, and that reflectance generally increases as a function of wavelength in amphiboles (Clark et al., 2007), we attribute most spectral features in CR-46 to eudialyte (Fig.

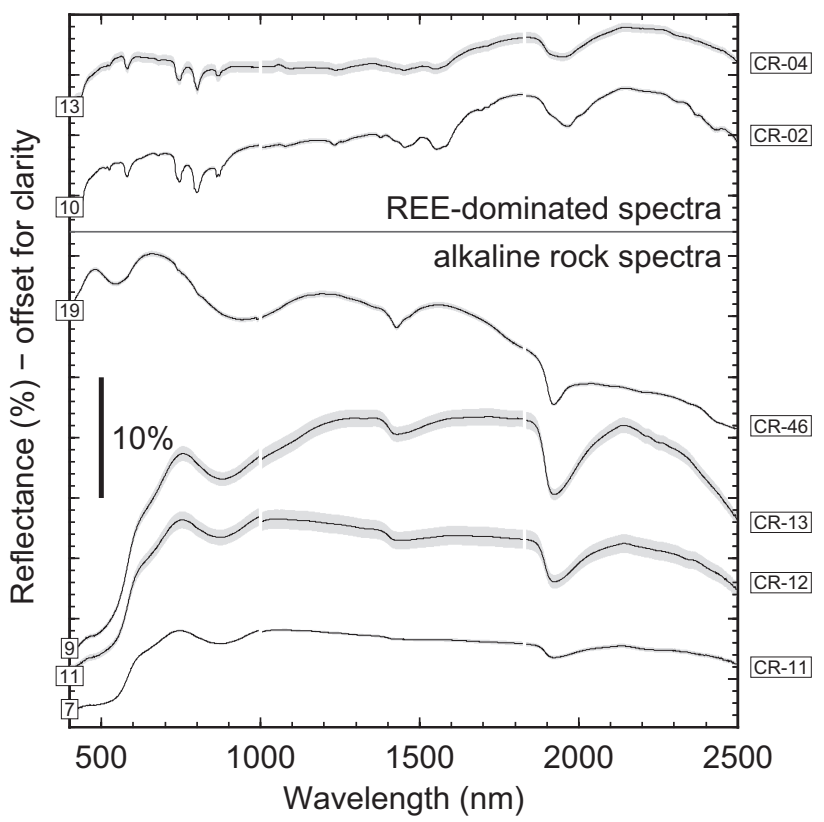

Fig. 10. Mean VNIR-SWIR spectra of samples dominated by REEs and of alkaline rock samples collected using an ASD spectroradiometer under laboratory conditions (CR-02, $n=94$; CR-04, $n=83$; CR-11, $n=21$; CR-12, $n$ $=37$, CR-13, $n=38$, CR-46, $n=73$ ). Gray envelopes show the standard errors of the mean spectra. Absolute reflectance values are shown at $400 \mathrm{~nm}$. Sample locations and rock types for spectra can be found in Tables 1-5. 
A1F). Eudialyte thus appears to be characterized by paired reflectance maxima at $\sim 480$ and $\sim 680 \mathrm{~nm}$ in line with previous measurements of eudialyte-bearing samples from the Red Wine Intrusive Suite (Kerr et al., 2011). Small absorption features centered at $\sim 744$ and $\sim 802 \mathrm{~nm}$ reflect the presence of $\mathrm{Nd}$ within the eudialyte.

\section{Thermal IR reflectance spectra}

A selection of representative thermal IR reflectance spectra are presented in Figure 11. Although absorption features associated with REEs are primarily located at VNIR-SWIR wavelengths, thermal IR spectra contain information crucial for lithologic mapping (Hook et al., 1994; Ninomiya et al., 2005). Thermal IR datasets can thus play important roles in identifying and delimiting carbonatite and alkaline complexes (Oppenheimer, 1998; Mars and Rowan, 2011). Reference thermal IR spectra for common rock-forming minerals are provided by Christensen et al. (2000) and Clark et al. (2007).

Carbonatite thermal IR spectra are readily distinguished from other igneous rock spectra by a prominent $\mathrm{CO}_{3}$ peak at $\sim 11.3 \mu \mathrm{m}$ (Christensen et al., 2000). Carbonate peaks are readily clearly visible in samples from Oka (CR-14), St. Honoré (CR-15), Tororo (CR-29), Kangankunde (CR-35), and Sokli (CR-42; Fig. 11). The only other significant features in these carbonate-dominated spectra are pairs of peaks centered at $\sim 9.0$ and $\sim 9.5 \mu \mathrm{m}$ separated by an absorption feature at $\sim 9.2 \mu \mathrm{m}$ that are best accounted for by the presence of phosphates, i.e., apatite (Christensen et al., 2000). A similarly positioned feature in sample CR-35 from Kangankunde REE-rich probably corresponds to the presence of the REE phosphate monazite-(Ce). Although a modest carbonate peak is observed in sample CR-36 from Mountain Pass, barite appears to have a stronger effect on the thermal IR spectrum: barite generates the small and large peaks centered at $~ 8.4$ and $\sim 9.1 \mu \mathrm{m}$, respectively (Clark et al., 2007).

Samples CR-02 and CR-11 from the Bayan Obo Banded Ore and Motzfeldt Peralkaline Microsyenite Suite contain little or no carbonate material and have thermal IR spectra dominated by silicate minerals (Christensen et al., 2000). Although relationships between silicate mineralogy and reflectance are complex, the broad series of peaks at 8.1 to $10.5 \mu \mathrm{m}$ in CR-11 can be ascribed to alkali feldspar and it its breakdown products. The slightly narrower peak at 8.6 to $10.6 \mu \mathrm{m}$ in CR-02 can be attributed to aegirine, though some fine features may relate to the presence of apatite $(\sim 9.2 \mu \mathrm{m})$ or even Sm ( 10 $\mu \mathrm{m}$; Clark et al., 2007).

\section{Spectral Features as Proxies for REE Mineralogy and Grade}

Although it is possible to resolve Pr and Sm absorption features in some REE-rich samples, features associated with Nd are both more prevalent and more prominent. Given that REEs have

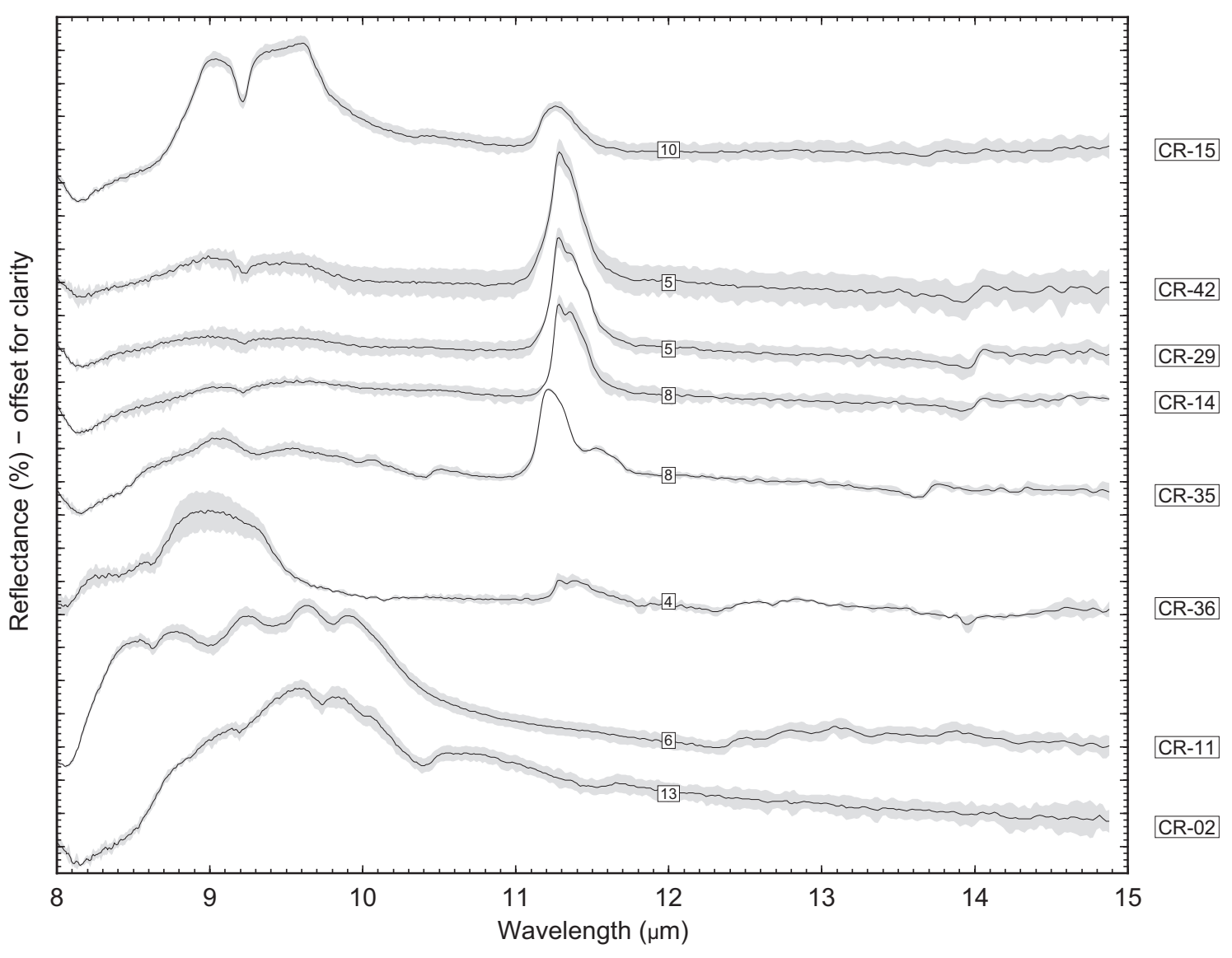

Fig. 11. Selected mean thermal IR reflectance spectra calculated from thermal emission spectra collected using a Fourier thermal IR spectrometer under laboratory conditions $(n=2-4)$ Gray envelopes show the standard errors of the mean spectra. Absolute reflectance values are shown at $12 \mu \mathrm{m}$. Sample locations and rock types for spectra can be found in Tables 1-5. 
very similar physicochemical properties and partitioning behaviors, Nd represents an ideal pathfinder element for much of the REE spectrum. While identifying heavy (H)REE absorption, features associated with Ho, Dy, and Er could enable relative abundances of LREE and HREE to be assessed, no features associated unambiguously with HREEs such as Ho, Dy and Er absorptions at $\sim 640, \sim 1,193$, and $\sim 650 \mathrm{~nm}$ were observed (e.g., Adams, 1965; Antonovich et al., 2007). Subsequent discussions thus focus on four prominent $\mathrm{Nd}$ absorptions centered at $~ 583$, $\sim 744, \sim 802$, and $\sim 871 \mathrm{~nm}$ that do not overlap significantly with other absorptions (Clark, 1995; Turner et al., 2014).

In order to relate properties of $\mathrm{Nd}$ absorption features to sample mineralogies and REE grades, background features relating to the main rock-forming mineralogy must first be removed. Simple ratios between the reflectance at absorption wavelengths and the reflectance at reference wavelengths cannot be used because of the highly nonunique shapes of the background spectra. $\mathrm{Nd}$ absorption features in all samples were therefore isolated using a continuum removal approach (Clark and Roush, 1984), where background spectra were estimated by fitting a third-order polynomial to spectra either side of the absorption features. The following continuum end points were used to isolate the $\sim 583, \sim 744, \sim 802$, and $\sim 871 \mathrm{~nm}$ absorptions from the combined effects of other spectral components respectively: 550 and 610,710 and 770,760 and 850 , and 850 and $910 \mathrm{~nm}$. The following properties were then estimated by fitting Gaussian curves to each background-subtracted Nd absorption feature: the central position of the absorption feature, i.e., peak position; full-width half at maximum; and absorption depth, i.e., peak height. Although Gaussian curves are unlikely to represent the true form of absorption features, they render fitting procedures internally consistent and reproducible (Clark and Roush, 1984). The area of each absorption feature was also calculated by subtracting areas under measured spectra from areas under background spectra. Finally, in order compare absorption feature areas between different samples, all Nd absorption areas were normalized to the mean reflectance within each wavelength interval.

\section{The effect of REE mineralogy on spectral properties}

$\mathrm{Nd}$ absorption features are located at the same wavelengths in samples with different REE mineralogies (Table 6). The mean central positions of absorption features within the four wavelength intervals investigated are as follows: 550 to $610 \mathrm{~nm}(n=$ 23), $583.0 \pm 1.2(1 \sigma) \mathrm{nm} ; 710$ to $780 \mathrm{~nm}(n=22), 744.4 \pm 1.3$ $(1 \sigma) \mathrm{nm} ; 770$ to $850 \mathrm{~nm}(n=32), 801.8 \pm 1.4(1 \sigma) \mathrm{nm}$; and 850 to $900 \mathrm{~nm}(n=17), 870.9 \pm 2.7(1 \sigma) \mathrm{nm}$. Deviation of absorption positions from mean absorption positions within each wavelength interval generally increase with decreased absorption depth, indicating that variability in calculated absorption locations is primarily related to analytical and processing errors and not to sample mineralogy. Our findings are thus consistent with previous studies that attribute $\mathrm{Nd}$ absorption features to mineral-independent electronic processes (Clark, 1995; Turner et al., 2014). However, subtle changes in the structure of $\mathrm{Nd}$ absorption features between different sample mineralogies may nevertheless reflect changes in bonding environments that relate to REE mineralogy.

Ancylite-bearing samples appear to show prominent shoulders on either side of absorption maxima at 583 to $584 \mathrm{~nm}$, which are also located at higher wavelengths than in bastnäsite- and monazite-dominated samples (581-582 nm; Table 6). Absorptions in apatite-dominated sample CR-18 are shifted to slightly higher wavelengths with respect to the other samples considered in this section; this trend does not appear to be reproduced in other apatite-dominated samples. The dominance of a single absorption centered at 870 to $871 \mathrm{~nm}$ rather than a doublet with absorptions centered on $~ 864$ and $\sim 871$ to $874 \mathrm{~nm}$ may distinguish apatite from other key REEbearing minerals, though the unambiguous detection of phosphates (i.e., apatite and monazite) is best achieved at thermal IR wavelengths (e.g., CR-15, Fig. 11). While representing potentially useful discriminators of mineralogy, fine structures of REE absorption features are likely to only be reproducible in REE-rich samples measured under laboratory conditions; these spectral minutiae are extremely difficult to resolve using remote sensing.

\section{The effect of REE grade on spectral properties}

$\mathrm{Nd}$ concentration correlates positively with $\mathrm{Nd}$ absorption depth across most samples (Fig. 12; Table 6). However, high abundances of magnetite mask $\mathrm{Nd}$ absorption features in some cases (e.g., CR-06 and CR-08). For absorptions centered at $\sim 583, \sim 744, \sim 802$, and $\sim 871 \mathrm{~nm} \mathrm{r}^{2}$ values are as follows: 0.492 , 0.674, 0.721 and 0.867. Sample CR-04 (Bayan Obo, Barite stage) is excluded from these fits because the surface from which spectroscopic data were collected is not representative of the bulk mineralogy. However, correlations between $\mathrm{Nd}$ concentration and $\mathrm{Nd}$ absorption area are generally stronger than those with Nd absorption depth: $\mathrm{r}^{2}=0.718,0.733,0.744$, and 0.805 for absorptions centered at $\sim 583, \sim 744, \sim 802$, and $\sim 871 \mathrm{~nm}$, respectively (Fig. 12; Table 6).

Although the correlation between Nd concentration and absorption area is strongest for the $~ 871-\mathrm{nm}$ absorption $\left(\mathrm{r}^{2}\right.$ $=0.805)$, few significant absorptions were identified at this wavelength, and the best fit line is very strongly weighted by the three high Nd samples. Nd absorption areas for absorptions centered at $\sim 744$ and $\sim 802 \mathrm{~nm}$ are therefore the most robust spectral proxies for $\mathrm{Nd}$ content. Using absorption areas rather than absorption depths as a measure of sample $\mathrm{Nd}$ content has the advantage of bypassing the addition of further errors during Gaussian peak fitting. Relationships between REE grade and spectral features are nevertheless subject to substantial uncertainty that is reflected in the scatter around best fit lines (Fig. 12). Causes for this scatter are difficult to isolate and may incorporate the following: sample heterogeneity, errors in whole-rock analyses, errors in spectroscopic analyses, and errors in continuum removal procedures. Furthermore, we do not account for grain size despite the strong effect it has on both the absolute reflectance of materials and the depth of absorption bands (Clark, 1995). Grain size can vary by orders of magnitude within the field of view of single ASD measurements (e.g., Fig. 3A) and the effects of grain size and composition cannot be separated with the current dataset. Nevertheless, $\mathrm{Nd}$ absorption features are readily identifiable in the samples from Bayan Obo (CR-02), Kangankunde (CR-16), and Mountain Pass (CR-36) that have the highest Nd concentrations measured in this study ( $\mathrm{Nd}>30,000 \mathrm{ppm}$; Table 6). These represent high-grade REE deposits. 

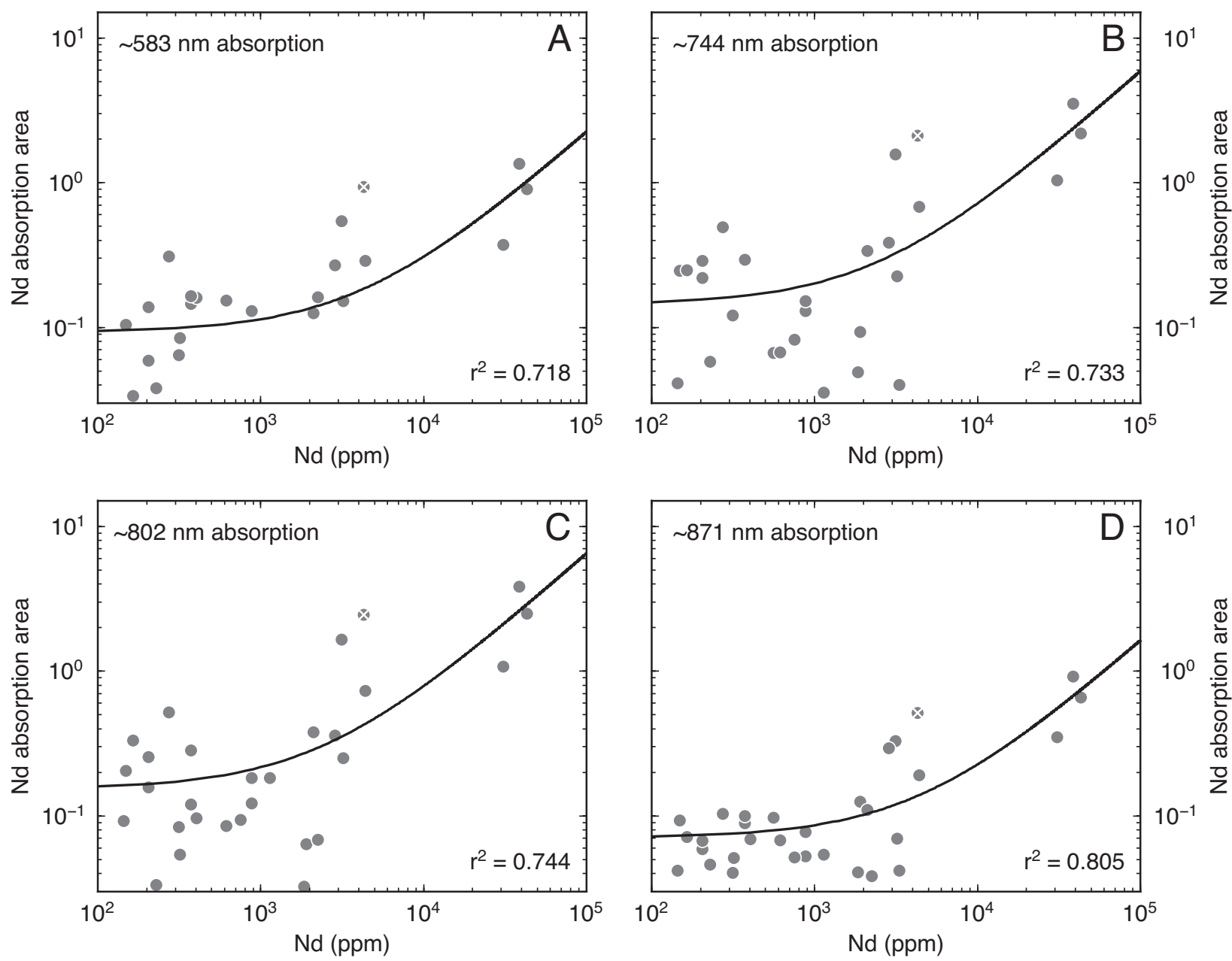

Fig. 12. Plots showing correlations between whole-rock $\mathrm{Nd}$ content and $\mathrm{Nd}$ absorption areas for four prominent $\mathrm{Nd}$ features centered at (A) $\sim 583 \mathrm{~nm},(B) \sim 744 \mathrm{~nm},(C) \sim 802 \mathrm{~nm}$, and (D) $\sim 871 \mathrm{~nm}$. Black lines show the results of linear regressions through the dataset, for which $\mathrm{r}^{2}$ values are shown in the bottom right of each plot. The data point with the white cross was excluded from the regression because the surface from which spectral data were collected is not representative of the bulk mineralogy.

\section{Detecting REEs Using Remote Sensing}

Spectral convolution: REE detectability by multispectral and hyperspectral sensors

Laboratory spectroscopy has a high spectral resolution at wavelengths relevant for detecting $\mathrm{Nd}(500-900 \mathrm{~nm})$. In order to determine whether REE absorption features could be detected by remote sensing, laboratory spectra were spectrally convolved (i.e., resampled) in order to simulate acquisition by a number of different multispectral and hyperspectral instruments. Multispectral sensors measure relatively few $(<20)$, broadly spaced, discontinuous spectral bands (Kramer, 2002), whereas hyperspectral sensors are defined by their high number $(>100)$ of narrow, contiguous bands that generate continuous spectra (Goetz et al., 1985). Four sensors were selected to encompass a range of well-known current and planned space- and airborne platforms: ASTER, Landsat-8 Operational Land Imager (OLI), EnMAP, and AVIRIS.

The multispectral ASTER instrument onboard Terra, the flagship satellite of the Earth Observing System (EOS) launched in 1999 and operated by the National Aeronautics and Space Administration (NASA), is the most widely used satellite for geologic mapping. ASTER operates in three bands at VNIR wavelengths with a ground resolution of $15 \mathrm{~m}$, six bands at SWIR wavelengths with a ground resolution of $30 \mathrm{~m}$, as well as in five bands at thermal IR wavelengths with a ground resolution of $90 \mathrm{~m}$. The spectral response functions of the ASTER instrument at VNIR-SWIR are provided at http://asterweb.jpl. nasa.gov/characteristics.asp. The multispectral Landsat-8 OLI platform, which is part of the Landsat Program that is jointly managed by NASA and the U.S. Geological Survey, images eight bands at VNIR-SWIR wavelengths, with a ground resolution of $15 \mathrm{~m}$. The spectral response functions for Landsat- 8 OLI are provided at http://landsat.gsfc.nasa.gov/?p=5779.

The launch of the German EnMAP hyperspectral satellite is planned for 2018 (Stuffler et al., 2007). EnMAP will carry two sensors capable of detecting 244 bands with a spectral resolution of $5 \mathrm{~nm}$ at VNIR wavelengths and $12 \mathrm{~nm}$ at SWIR wavelengths (Guanter et al., 2015). The ground resolution will be $30 \mathrm{~m}$. Measured spectral response functions are not yet available for EnMAP, so synthetic spectral response 
functions were approximated from expected band centers and FWHM provided on the project website (www.enmap. org/sites/default/files/pdf/Table_EnMAP_Specs.pdf). AVIRIS is an airborne hyperspectral instrument developed by NASA's Jet Propulsion Laboratory (JPL) that has 224 contiguous spectral bands with wavelengths from 400 to $2,500 \mathrm{~nm}$ and a spatial resolution ranging from 4 to $18 \mathrm{~m}$, depending on which aircraft it is flown. Spectral response functions for AVIRIS are provided at https://directory.eoportal.org/web/eoportal/ airborne-sensors/aviris. AVIRIS is taken to be representative of typical airborne hyperspectral sensors, sharing similar characteristics with other systems such as HyMap ${ }^{\circledR}$, though we note that some systems such as CASI can achieve higher spatial resolutions (Black et al., 2014).

Convolved reflectance values $L$ at a given band $i$ using the following equation:

$$
L_{i}=\frac{\int L_{s}(\lambda) r_{i}(\lambda) \delta \lambda}{}
$$
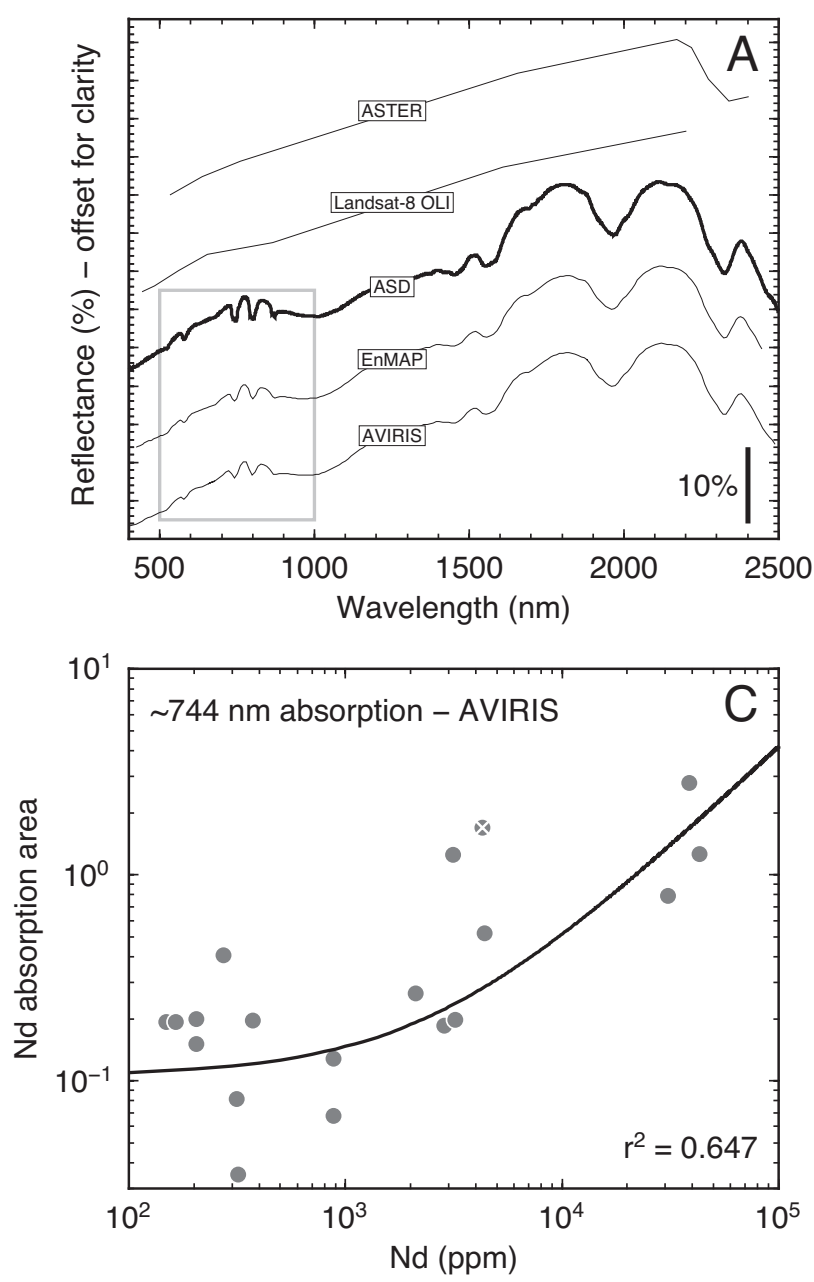

\section{$\int r_{i}(\lambda) \delta \lambda$}

where $L_{s}(\lambda)$ is the reflectance at band $i$ and wavelength $\lambda, r_{i}(\lambda)$ is the spectral response functions of band $i$ and wavelength $\lambda$, over the wavelength interval of the sample $\delta \lambda$.

Convolved spectra from sample CR-35, which shows appreciable $\mathrm{Nd}$ absorption features, indicate that neither ASTER nor Landsat-8 OLI have sufficient spectral resolutions to distinguish narrow REE features, despite the location of bands at relevant VNIR wavelengths (Fig. 13A). In contrast with the observations of Rowan and Mars (2003) from Mountain Pass, the depression in average reflectance at 700 to $900 \mathrm{~nm}$ is insufficient to discern the presence of REEs. Furthermore, the background spectra of many samples in this region are also strongly affected by Fe absorptions at these wavelengths. Nevertheless, a significant advantage of ASTER for geologic mapping over the Landsat-8 OLI platform is the location of bands at $>2,200 \mathrm{~nm}$ that enable the $\mathrm{CO}_{3}$ absorption feature centered at $\sim 2,300 \mathrm{~nm}$ to be discerned. Data from some
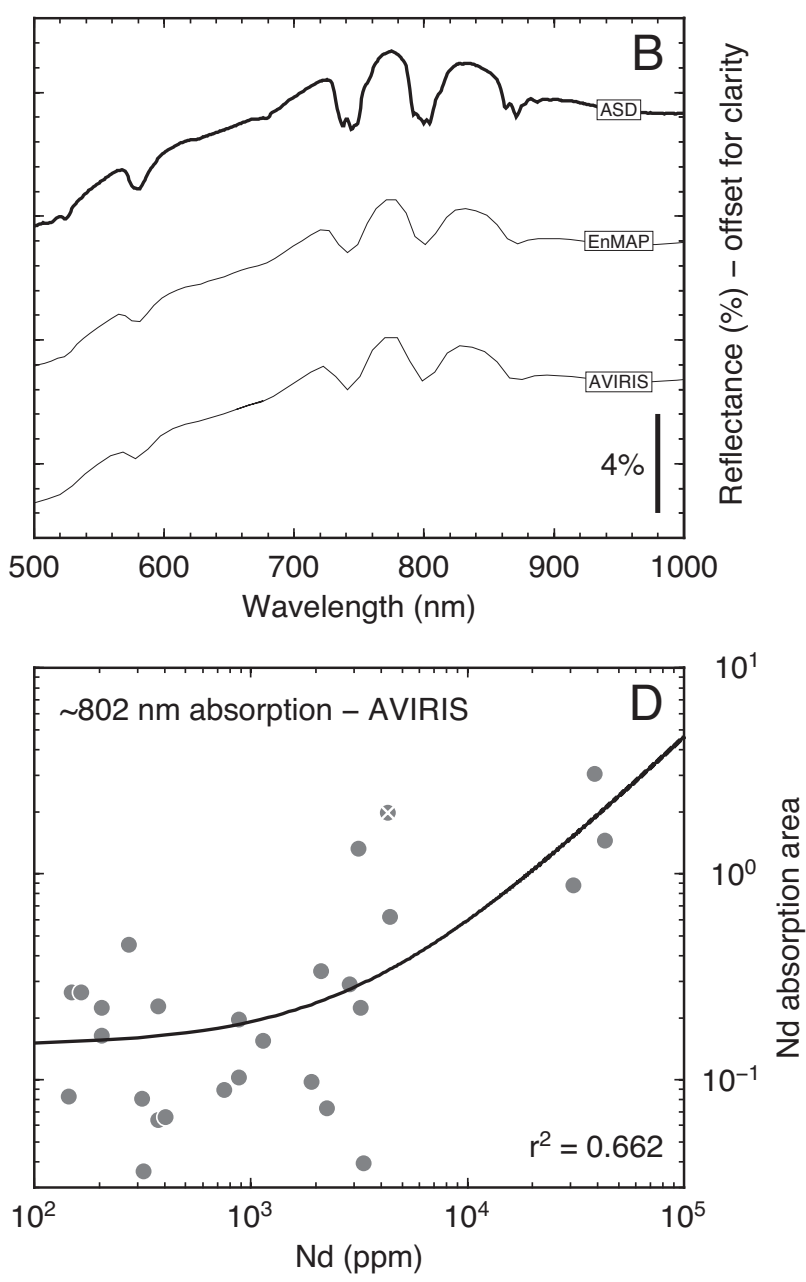

Fig. 13. A. Plot showing the effect of convolving (i.e., resampling) an ASD spectrum to the spectral response functions of a range of multispectral (ASTER and Landsat-8 OLI) and hyperspectral (EnMAP and AVIRIS) instruments. While most spectral information is lost in the convolved ASTER and Landsat-8 OLI spectra, much information is retained in the convolved EnMAP and AVIRIS spectra. B. Zoomed in region of plot (A), showing how the coarse structure of the four largest Nd absorption features is retained following spectral convolution. Fine features, such as the multiple absorptions within the main absorptions centered at $\sim 744 \mathrm{~nm}, \sim 802 \mathrm{~nm}$, and $\sim 871 \mathrm{~nm}$ are not retained in the convolved data. C. and D. Plots showing the correlations between $\mathrm{Nd}$ absorption area in spectra convolved to the AVIRIS spectral response function and whole-rock Nd content for absorptions centered at (C) $\sim 744 \mathrm{~nm}$ and (D) $\sim 802 \mathrm{~nm}$. 
multispectral instruments are thus capable of identifying and delimiting carbonatites but are unable to provide useful information about their REE contents (Rowan and Mars, 2003; Mars and Rowan, 2011).

In contrast, the spectral resolutions of AVIRIS and EnMAP are sufficient to resolve four prominent $\mathrm{Nd}$ absorptions between 550 and $900 \mathrm{~nm}$ (Fig. 13A, B). Although the coarser spectral resolution of remote sensing instruments with respect to the ASD ( 7 vs. 3-6 nm) results in smoothing of absorptions, individual absorption features remain clear and distinct. However, the spectral resolution of convolved data is insufficient to fit Gaussian curves to background-subtracted $\mathrm{Nd}$ features in a consistent manner. Nevertheless, relationships between the area of $\mathrm{Nd}$ absorption features centered at both $\sim 744$ and $\sim 802 \mathrm{~nm}$, and REE grade remain strong (Fig. 13C, D). EnMAP and AVIRIS thus have the necessary characteristics to detect $\mathrm{Nd}$ at economically relevant grades in range of geologic samples.

\section{REE detectability as a function of signal-to-noise ratio}

While EnMAP and AVIRIS have sufficient spectral resolutions to detect $\mathrm{Nd}$ in REE-rich samples, it is important to assess whether the $\mathrm{Nd}$ absorptions are detectable at realistically attainable signal-to-noise ratios. EnMAP spectra are expected to reach signal-to-noise ratios of $\sim 500: 1$ at $495 \mathrm{~nm}$ and $\sim 150: 1$ at 2,200 nm (www.enmap.org/sites/default/files/ pdf/Table_EnMAP_Specs.pdf), though signal-to-noise ratios could be significantly lower during routine operations. Signalto-noise ratios of AVIRIS spectra have improved significantly since the system's introduction in 1989, and can now reach in excess of 1000:1 at VNIR wavelengths and 500:1 at SWIR wavelengths under optimum conditions (Green et al., 1998; Veraverbeke et al., 2014). In order to investigate the relationship between $\mathrm{Nd}$ detectability and spectral signal-to-noise ratios, varying amounts of noise were added to convolved spectra using the method of Bioucas-Dias and Nascimento (2008) in order to generate a suite of spectra with signal-tonoise ratios spanning the range 10 to $500: 1$.

The effects of adding synthetic noise to convolved spectra are summarized in Figure 14, illustrating how the areas of $\mathrm{Nd}$ absorptions centered on $\sim 744$ and $~ 802 \mathrm{~nm}$ deviate from the areas calculated for convolved ASD when various amounts of synthetic noise are added. Data are shown for samples CR-16 and CR-49 that are moderately and highly enriched in REEs, respectively. On average, differences in $\mathrm{Nd}$ absorption area between ASD and synthetic noisy spectra $(\Delta)$ increase as signal-to-noise ratio decreases: below a signal-to-noise ratio of $250: 1, \Delta$ increases at an increasing rate with decreasing signal-to-noise ratio.

At a signal-to-noise ratio of 250:1, $\Delta$ values for absorptions centered at $\sim 744$ and $\sim 802 \mathrm{~nm}$ are $\sim 20 \%$ for CR-16 and $\sim 10 \%$ for CR-49. The lower $\Delta$ values for CR-49 are consistent with the greater abundance of REE minerals in this sample. The $\Delta$ values for spectra convolved to the AVIRIS spectral response functions are generally slightly lower than $\Delta$ values for spectra convolved to the EnMAP spectral response functions because of the higher spectral resolution of the AVIRIS system. Relative errors in Nd absorption areas are thus likely to be 10 to $20 \%$ at signal-to-noise ratios of $\sim 250$ : 1 when imaging REE-rich materials ( $\mathrm{Nd}>30,000 \mathrm{ppm}$ ).
As the signal-to-noise ratio of convolved spectra decreases below 250:1, the strength of correlations between Nd absorption area and $\mathrm{Nd}$ content decreases for absorptions centered at both $\sim 744$ and $\sim 802 \mathrm{~nm}$ (Fig. 14C, D). REE detection will thus be most robust in datasets with signal-to-noise ratios in excess of $\sim 250: 1$, though detection at lower signal-to-noise ratios may be possible.

\section{Atmospheric inferences}

While multispectral imaging bands are generally placed at wavelengths that avoid atmospheric absorption features (i.e., within "atmospheric windows"), hyperspectral instruments collect continuous spectra that encompass numerous atmospheric absorptions (Goetz, 2009). Hyperspectral datasets therefore require careful correction for atmospheric absorption effects generated by the presence of various species, including $\mathrm{H}_{2} \mathrm{O}, \mathrm{O}_{3}, \mathrm{CO}_{2}, \mathrm{O}_{2}$ and $\mathrm{CH}_{4}$, before they can be interpreted (e.g., Gao et al., 1993, 2009). In order to assess the likely impact of atmospheric interferences on the imaging of REE deposits, we used the MODTRAN ${ }^{\circledR}$ radiative transfer model. This simulates atmospheric conditions relevant to hyperspectral remote sensing along the coastal strips of Greenland, a likely target for remote sensing campaigns (Berk et al., 1998, 2005). The model was parameterized to simulate a $50^{\circ}$ solar elevation angle, a sensor with nadir viewing of a target at sea level and a subarctic atmospheric profile with a maritime atmospheric profile. The results of MODTRAN ${ }^{\circledR}$ simulations are shown in Figure 15, where atmospheric transmission is plotted as a function of wavelength in order to illustrate absorption features generated by a number of important atmospheric gases and aerosols.

The largest atmospheric features are $~ 200$-nm-wide $\mathrm{H}_{2} \mathrm{O}$ absorptions centered at $\sim 1,400$ and $\sim 1,900 \mathrm{~nm}$ that block all transmission at these wavelengths; no geologic information can be recovered at $\sim 1,300$ to 1,500 or $\sim 1,800$ to $2,000 \mathrm{~nm}$. Substantial $\mathrm{H}_{2} \mathrm{O}$ absorptions (transmission $>0.4$ ) also occur at $950,1,150$, and 2,500 $\mathrm{nm}$ that degrade geologic interpretations (Fig. 15). Although the major atmospheric absorptions occur at wavelengths greater than main $\mathrm{Nd}$ absorptions, smaller atmospheric features occur within 580- to $870-\mathrm{nm}$ range. Specifically, modest $\mathrm{H}_{2} \mathrm{O}$ absorptions centered at $\sim 720$ and $820 \mathrm{~nm}$ have the potential to complicate the identification of $\mathrm{Nd}$ absorption features centered at 744 and $~ 802 \mathrm{~nm}$. A narrow but deep $\mathrm{O}_{3}$ absorption feature $770 \mathrm{~nm}$ may also interfere with the identification of absorptions at $\sim 744$ and $\sim 802 \mathrm{~nm}$, and a broad $\mathrm{O}_{3}$ absorption centered at $\sim 590 \mathrm{~nm}$ may affect the ability to resolve absorptions centered at $\sim 583$ $\mathrm{nm}$. Even though the precise nature of atmospheric corrections required will vary from campaign to campaign this simplistic treatment demonstrates that there is significant atmospheric transmission at the wavelengths relevant to the identification of $\mathrm{Nd}$. Thus, if high-quality atmospheric corrections are applied to datasets with high signal-to-noise ratios, Nd features should remain detectable, though ground calibration may also be required to sufficiently reduce radiative transfer atmospheric residuals.

\section{Spatial resolution: Outcrop versus pixel sizes}

Having established that $\mathrm{Nd}$ should be detectable at high grades by hyperspectral instruments under optimal conditions, it is 

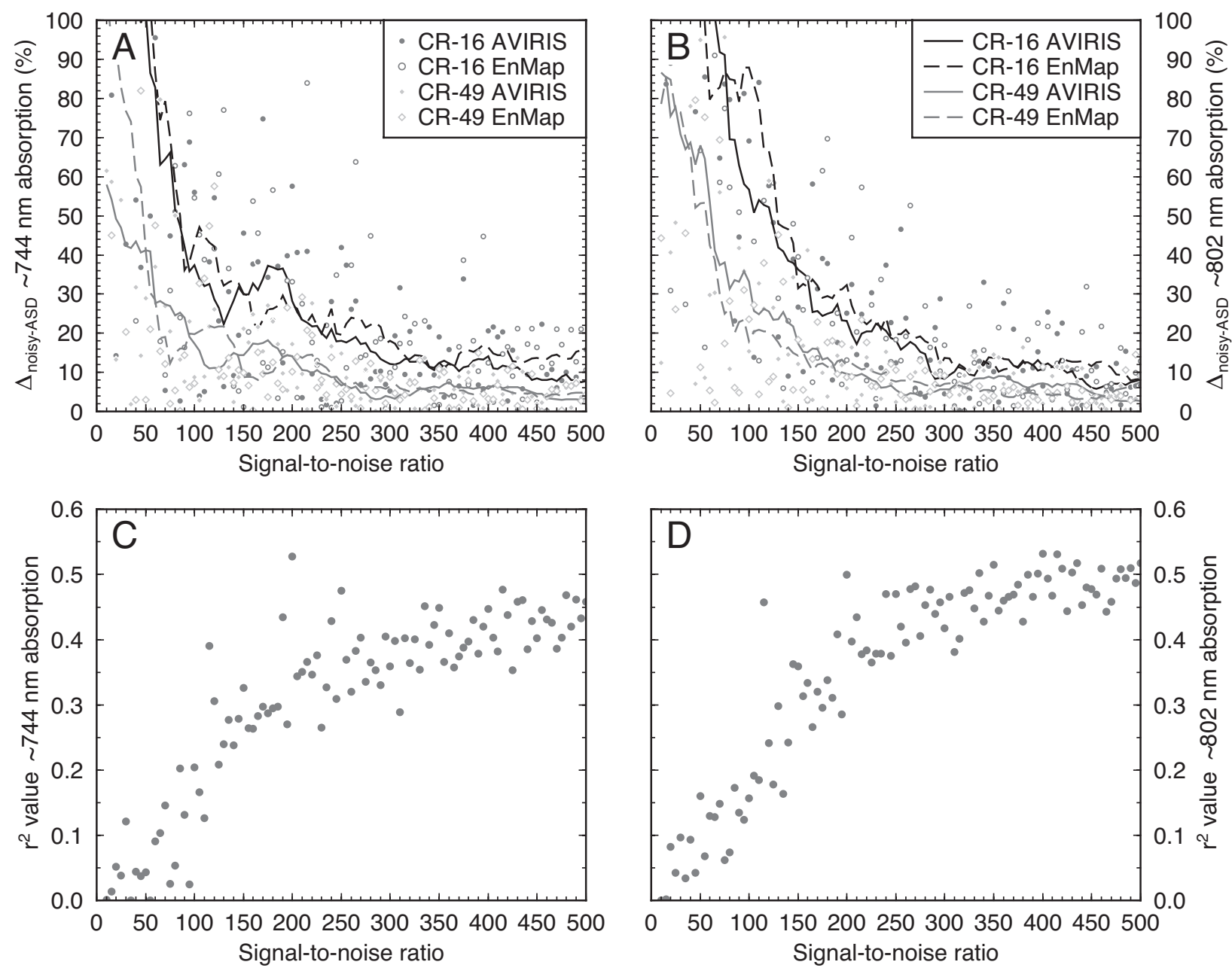

Fig. 14. A. and B. Plots showing how the area of absorption features in convolved spectra diverge from the area of absorption features measured by ASD as varying amounts of synthetic noise are added. The absolute difference between noisy convolved

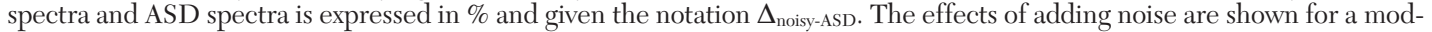
erately REE rich sample (CR-16) and a very REE rich sample (CR-49). The relationship between spectra signal-to-noise ratio and $\Delta_{\text {noisy-ASD }}$ are shown for the $\sim 744 \mathrm{~nm}$ and $\sim 802 \mathrm{~nm}$ absorptions in (A) and (B), respectively. Solid and dashed lines show the smoothed variation of $\Delta_{\text {noisy-ASD }}$ with signal-to-noise ratio for data convolved to the AVIRIS and EnMAP spectral response functions, respectively. C. and D. Plots illustrating how adding varying amounts of synthetic noise to spectra convolved to the AVIRIS spectral response function degrades correlations between Nd absorption area and whole-rock Nd content for absorptions centered at $(\mathrm{C}) \sim 744 \mathrm{~nm}$ and $(\mathrm{D}) \sim 802 \mathrm{~nm}$.

important to assess whether their spatial resolution is sufficient to detect zones of REE mineralization. Although some REE deposits, such as the Sulphide Queen Orebody at Mountain Pass and Bayan Obo outcrop on hundreds of meter length scales (Castor, 2008; Smith et al., 2015), most REE occurrences are meter-scale dikes and veins (Mitchell, 2005). It is therefore likely that the outcropping portions of most REE deposits will be too small to be detected using satellitebased platforms: EnMAP is expected to have a spatial resolution of $30 \mathrm{~m}$ at VNIR wavelengths. Airborne platforms can achieve the meter-scale spatial resolutions required: up to $\sim 4$ and $\sim 0.5 \mathrm{~m}$ for AVIRIS and CASI, respectively (Kruse, 2012; Black et al., 2014), and hence represent a much better tool for REE mapping. Perhaps the greatest opportunity for REE remote sensing would involve the deployment of hyperspectral instruments on unmanned aerial vehicles. While still at early stages of development, unmanned aerial vehicles could enable hyperspectral mapping to be carried out at the centimeter scale (Hugenholtz, 2012; Colomina and Molina, 2014), making it possible to map $\mathrm{Nd}$ grade across whole deposits. Indeed, the feasibility of such fine-scale mapping has already been demonstrated using ground-based hyperspectral imaging of monazite enrichments in the Fen complex (Boesche et al., 2015).

\section{Applications}

Our results indicate that direct detection of REEs by hyperspectral imaging will be best suited to high-grade deposits, such as carbonatites that contain discrete REE minerals. It would also be applicable to other high-grade igneous and metamorphic (Steenkampskraal-type monazite) and hydrothermal deposits. However, given the general relationship between Nd absorption depth and abundance (Fig. 12), it will be more difficult to make the technique sufficiently robust for 


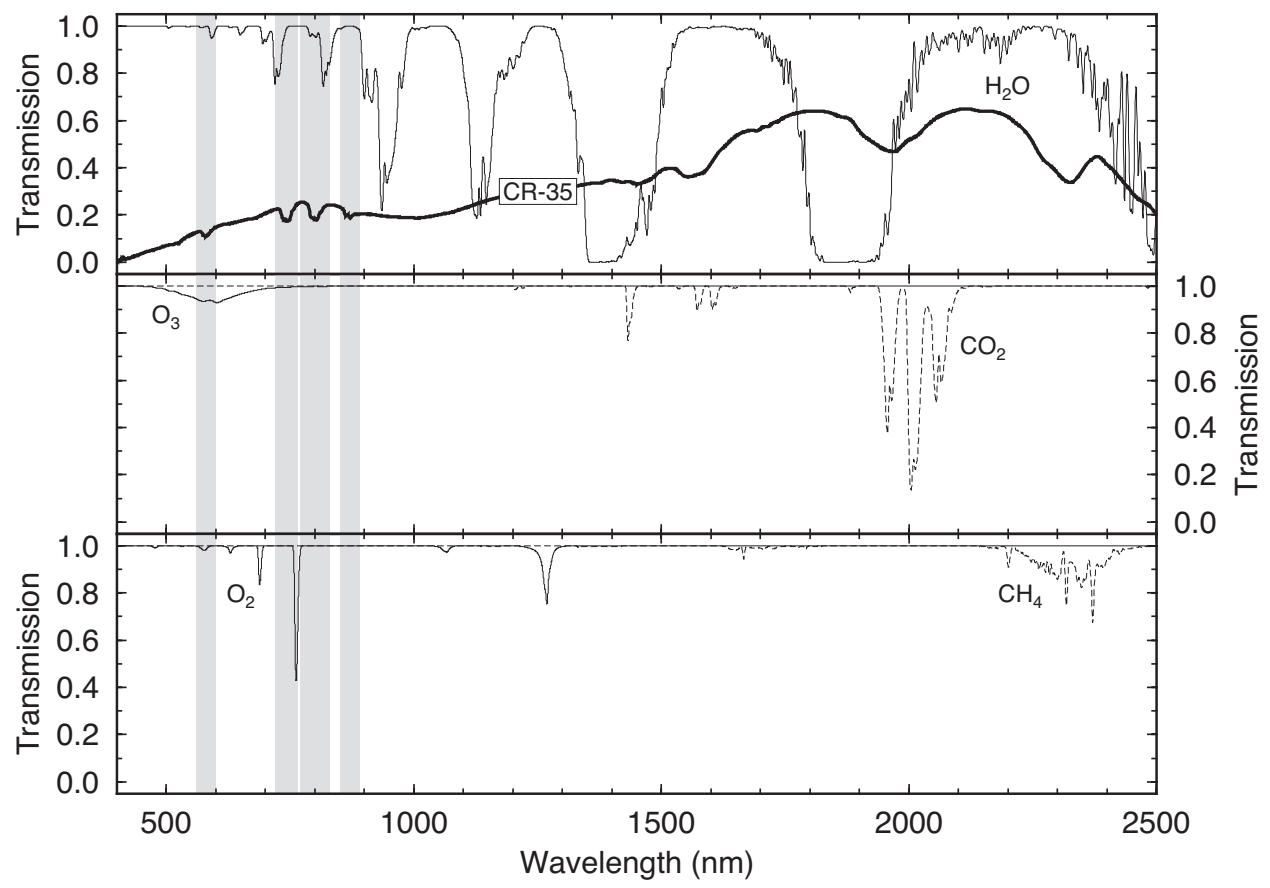

Fig. 15. Plot summarizing the transmission of major atmospheric gases and aerosols at VNIR-SWIR wavelengths simulated, using the MODTRAN radiative transfer model (Berk et al., 1998, 2005). The model was parameterized to simulate a $50^{\circ}$ solar elevation angle, a sensor with nadir viewing of a target at sea level, and the subarctic atmospheric profile with a maritime aerosol model; indicative of the likely conditions in Greenland. A typical REE-rich sample spectrum is shown for reference. Although atmospheric absorption features are present at the wavelengths relevant to REE detection, none reduce transmission to zero, as occurs at higher wavelengths.

identifying lower grade REE deposits, such as those currently of interest for their higher proportions of mid and heavy REEs, in either carbonatitic or silicate systems. Although the technique could detect $\mathrm{Nd}$ in the eudialyte-bearing kakortokite tested here, further development is necessary to correlate $\mathrm{Nd}$ absorption features with the lower $\mathrm{Nd}$ concentrations characteristic of nepheline syenites (Wall, 2014). The same holds true for apatite-bearing deposits where whole-rock REE concentrations will be below levels where correlations between spectral properties and $\mathrm{Nd}$ content become clear: apatite typically contains only up to 1 or 2 wt $\%$ ¿REO.

Nevertheless, hyperspectral remote sensing is potentially superior to radiometric surveys, a traditional REE exploration tool in which radioactivity from $\mathrm{U}$ and $\mathrm{Th}$ serve as pathfinders to REE-rich rocks. However, $\mathrm{U}$ and $\mathrm{Th}$ are penalty elements and an ideal REE deposit has high REE but low U and Th. Hyperspectral imaging can target REEs directly and help find deposits low in radioactive elements.

$\mathrm{Nd}$ is a LREE, and the main driver for the REE market owing to its use in high-strength permanent magnets, but there is also a current need to find new sources of HREEs (Hatch, 2012): using Nd as a pathfinder element unfortunately makes the technique inapplicable to xenotime- $(\mathrm{Y})$ deposits, such as Lofdal (Namibia) and Browns Range (Australia) because xenotime-(Y) contains very low Nd contents. At Lofdal, however, there are also LREE minerals in addition to xenotime-(Y), so direct hyperspectral imaging of LREEs might be a guide to HREE-rich dikes and surrounding mineralization. Hyperspectral imaging has been applied to exploration at Lofdal but only for the detection of carbonate, not as a direct indicator of REE content (Swinden and Siegfried, 2011; Do Cabo, 2014). Nepheline syenite deposits are also often cited as HREE deposits. While alkaline rocks tend to contain minerals with higher HREE/LREE ratios than typical carbonatite deposits (e.g., eudialyte), HREE minerals are generally scarce and whole-rock Nd concentrations remain appreciable with respect to HREE concentrations. Nd could thus still be used in the exploration of these deposits if problems associated with of detecting low $\mathrm{Nd}$ concentrations can be overcome. While there is potential for detecting HREEs by reflectance spectroscopy (e.g., Dy, Ho, and Er; Adams, 1965; Antonovich et al., 2007), we did not identify these elements in our LREE-dominated samples. In any case, published reference spectra for HREE-rich materials are sparse and obtaining such spectra thus represents a key future objective in the development of REE remote sensing.

\section{Conclusions}

$\mathrm{Nd}$ absorption features, which are the strongest LREE absorption features at VNIR-SWIR wavelengths, have been identified in reflectance spectra collected from a suite of predominantly carbonatitic samples with variable REE contents. Absorption features centered at wavelengths of $\sim 583, \sim 744$, $\sim 802$, and $\sim 871 \mathrm{~nm}$ were detected by laboratory reflectance spectroscopy in samples with $\mathrm{Nd}$ concentrations $>1,000 \mathrm{ppm}$. $\mathrm{Nd}$ absorption features are dominantly elemental in nature and do not change significantly as a function of host mineralogy at the FWHM of an ASD spectroradiometer. Continuum removal was performed using a third-order polynomial fit around the wavelength brackets of each $\mathrm{Nd}$ absorption 
feature; this allowed for the subtraction of the background spectrum which isolated the $\mathrm{Nd}$ absorption feature(s) and suppressed the spectral variability associated with changes in sample composition and mineralogy. $\mathrm{Nd}$ absorption features depth and area correlate positively with whole-rock $\mathrm{Nd}$ content, though correlations between $\mathrm{Nd}$ concentration and $\mathrm{Nd}$ absorption area are generally more robust. Absorptions centered at wavelengths of $\sim 744$ and $\sim 802 \mathrm{~nm}$ give the most reliable fits $\left(\mathrm{r}^{2} \sim 0.7\right)$. Nd absorption features in VNIR reflectance spectra thus represent a crude proxy for whole-rock $\mathrm{Nd}$ content under laboratory conditions.

Convolving laboratory reflectance spectra to the spectral response functions of various remote sensing instruments demonstrates that, while multispectral platforms lack the spectral resolution to resolve $\mathrm{Nd}$ absorption features at geologically relevant concentrations, hyperspectral platforms such as AVIRIS and EnMAP have the spectral resolution needed to detect narrow Nd absorptions. Correlations between whole-rock $\mathrm{Nd}$ content and $\mathrm{Nd}$ absorption areas are moderately strong following spectral convolution $\left(\mathrm{r}^{2} \sim 0.6\right)$. The addition of synthetic noise to convolved spectra indicates that spectral signal-to-noise ratios of at least $~ 250: 1$ are required for relationships between $\mathrm{Nd}$ grade and spectral properties to remain robust, i.e., $\mathrm{Nd}$ features will only be resolvable in high-quality datasets. Fortunately, the results of simple atmospheric modeling confirm that atmospheric transmission mostly remains above 0.8 within the crucial 500- to $900-\mathrm{nm}$ wavelength interval within which $\mathrm{Nd}$ may be detected. A final consideration of the spatial resolution of different hyperspectral systems shows that, while satellite-based instruments currently lack the spatial resolution to detect the meter-scale REE enrichments that occur within carbonatites, many airborne platforms will not suffer from the same limitations. With high-quality datasets (signal-to-noise $>250: 1$ ) and well-constrained atmospheric models it should be possible to image $\mathrm{Nd}$ in high-grade, carbonatite-hosted REE deposits (Nd $\sim 30,000 \mathrm{ppm}$ ) regardless of REE host mineralogy using currently available technology. While our proposed technique is dependent on the presence of $\mathrm{Nd}$, and may be unsuitable for detecting some HREE-rich deposits, it offers a key advantage over radiometric surveys allowing the detection of REEs to be isolated from the detection of radioactive penalty elements. Mounting hyperspectral sensors on unmanned aerial vehicles offers the exiting possibility of being able to map REE grade across whole deposits at resolutions as fine as a few centimeters in the near future.

\section{Acknowledgments}

We thank Jon Russill and Adrian Finch from SRK Consulting (UK) Ltd. and the University of St. Andrews, respectively, for providing samples. Alan Woolley and David Smith helped with the loan of samples from the Natural History Museum in London. Dan Pemberton and Rob Theodore helped with the loan of samples from the Harker Collection at the University of Cambridge. Chris MacLellan provided invaluable guidance with the collection of spectroscopic data at the Natural Environment Research Council Field Spectroscopy Facility at the University of Edinburgh. Nick Marsh at the University of Leicester carried out the XRF analyses on our highly challenging sample suite. We also thank Rob Clark, Jason Day, and Iris Buisman at the University of Cambridge for their assistance with sample preparation, SEM imaging, and EDX analyses. Todd Hoefen and Lyle Mars provided detailed and highly constructive reviews that significantly improved the quality of the manuscript. Finally, we thank Larry Meinert for his efficient editorial handling.

DAN and the project as a whole were supported by funds from the University of Cambridge Higher Education Innovation Funding (HEIF) allocation, as part of the effort to establish a new Innovation Centre for the Environment located at the British Antarctic Survey (BAS). MB was supported by a Natural Environment Research Council (NERC) Research Studentship (NE/K50094X/1).

\section{REFERENCES}

Adams, J.W., 1965, The visible region absorption spectra of rare earth minerals: American Mineralogist, v. 50, p. 356-366.

Andersen, T., 1988, Evolution of peralkaline calcite carbonatite magma in the Fen complex, southeast Norway: Lithos, v. 22, p. 99-112.

Antonovich, V.P., Stoyanova, I.V., Chivireva, N.A., Timukhin, E.V., Zinchenko, V.F., and Efryushina, N.P., 2007, Identification and quantitative determination of some inorganic lanthanide compounds by diffuse reflectance spectroscopy: Journal of Analytical Chemistry, v. 62, p. 238-244.

Bailey, J.C., Gwozdz, R., Rose-Hansen, J., and Sørensen, H., 2001, Geochemical overview of the Ilímaussaq alkaline complex, South Greenland: Geology of Greenland Survey Bulletin, v. 190, p. 35-53.

Basu, N.K., and Mayila, A., 1986, Petrographic and chemical characteristics of the Panda Hill carbonatite complex, Tanzania: Journal of African Earth Sciences, v. 5, p. 589-598.

Bedini, E., 2009, Mapping lithology of the Sarfartoq carbonatite complex, southern West Greenland, using HyMap imaging spectrometer data: Remote Sensing of Environment, v. 113, p. 1208-1219.

Berk, A., Bernstein, L.S., Anderson, G.P., Acharya, P.K., Robertson, D.C., Chetwynd, J.H., and Adler-Golden, S.M., 1998, MODTRAN cloud and multiple scattering upgrades with application to AVIRIS: Remote Sensing of Environment, v. 65, p. 367-375.

Berk, A. et al., 2005, MODTRAN5: A reformulated atmospheric band model with auxiliary species and practical multiple scattering options: Proceedings of SPIE, v. 5655, p. 88-95.

Bioucas-Dias, J.M., and Nascimento, J.M.P., 2008, Hyperspectral subspace identification: IEEE Transactions on Geoscience and Remote Sensing, v. 46 , p. $2435-2445$.

Black, M., Fleming, A., Riley, T.R., Ferrier, G., Fretwell, P., McFee, J., Achal, S., and Diaz, A.U., 2014, On the atmospheric correction of Antarctic airborne hyperspectral data: Remote Sensing, v. 6, p. 4498-4514.

Boesche, N., Rogass, C., Lubitz, C., Brell, M., Herrmann, S., Mielke, C., Tonn, S., Appelt, O., Altenberger, U., and Kaufmann, H., 2015, Hyperspectral REE (rare earth element) mapping of outcrops-applications for neodymium detection: Remote Sensing, v. 7, p. 5160-5186.

Bradshaw, C., 1988, A petrographic, structural and geochemical study of the alkaline igneous rocks of the Motzfeldt centre, south Greenland: Durham, UK, Durham University, 401 p.

Brooker, R.A., and Kjarsgaard, B.A., 2011, Silicate-carbonate liquid immiscibility and phase relations in the system $\mathrm{SiO}_{2}-\mathrm{Na}_{2} \mathrm{O}-\mathrm{Al}_{2} \mathrm{O}_{3}-\mathrm{CaO}-\mathrm{CO}_{2}$ at 0.1 2.5 GPa with applications to carbonatite genesis: Journal of Petrology, v. 52 , p. 1281-1305.

Broom-Fendley, S., Styles, M.T., Appleton, J.D., Gunn, G., and Wall, F. 2016, Evidence for dissolution-reprecipitation of apatite and preferential LREE mobility in carbonatite-derived late-stage hydrothermal processes: American Mineralogist, v. 101, p. 596-611, http://www.minsocam.org/msa/ ammin/toc/2016/index.html?issue_number=03.

Do Cabo, V.N., 2014, Geological, mineralogical and geochemical characterisation of the heavy rare earth-rich carbonatites at Lofdal, Namibia: Exeter, UK, University of Exeter, 548 p.

Campbell, L.S., and Henderson, P., 1997, Apatite paralgenesis in the Bayan Obo REE-Nb-Fe ore deposit: Lithos, v. 42, p. 89-103.

Castor, S.B., 2008, The Mountain Pass rare-earth carbonatite and associated ultrapotassic rocks, California: Canadian Mineralogist, v. 46, p. 779-806.

Chakhmouradian, A.R., and Zaitsev, A.N., 2012, Rare earth mineralization in igneous rocks: Sources and processes: Elements, v. 8, p. 347-353. 
Christensen, P.R., Bandfield, J.L., Hamilton, V.E., Howard, D.A., Lane, M.D., Piatek, J.L., Ruff, S.W., and Stefanov, W.L., 2000, A thermal emission spectral library of rock-forming minerals: Journal of Geophysical Research, v. 105 , p. $9735-9739$

Clark, R.N., 1995, Reflectance spectra: Rock physics and phase relations. A handbook of physical constants: American Geophysical Union Reference Shelf 3, p. 178-188.

Clark, R.N., and Roush, T.L., 1984, Reflectance spectroscopy: Quantitative analysis techniques for remote sensing applications: Journal of Geophysical Research, Solid Earth, v. 89, p. 6329-6340.

Clark, R.N., Swayze, G., Wise, R., Livo, E., Hoefen, T., Kokaly, R., and Sutley, S.J.J., 2007, U.S. Geological Survey Digital Spectral Library splib06a: U.S. Geological Survey, Digital Data Series 231, http://speclab.cr.usgs.gov/ spectral.lib06.

Colomina, I., and Molina, P., 2014, Unmanned aerial systems for photogrammetry and remote sensing: A review: International Society for Photogrammetry and Remote Sensing, ISPRS Journal of Photogrammetry and Remote Sensing, v. 92, p. 79-97.

Dawson, J.B., and Hinton, R.W., 2003, Trace-element content and partitioning in calcite, dolomite and apatite in carbonatite, Phalaborwa, South Africa: Mineralogical Magazine, v. 67, p. 921-930.

Dieke, G.H., 1970, Spectra and energy levels of rare earth ions in crystals: American Journal of Physics, v. 38, p. 399.

Drew, L.J.J., Qingrun, M., and Weijun, S., 1990, The Bayan Obo iron-rareearth-niobium deposits, Inner Mongolia, China: Lithos, v. 26, p. 43-65.

Eby, G.N., Lloyd, F.E., and Woolley, A.R., 2009, Geochemistry and petrogenesis of the Fort Portal, Uganda, extrusive carbonatite: Lithos, v. 113, p. 785-800

Erdosh, G., 1979, The Ontario carbonatite province and its phosphate potential: Economic Geology, v. 74, p. 331-338.

Eriksson, S.C., 1989, Phalaborwa: A saga of magmatism, metasomatism and miscibility, in Bell, K., ed., Carbonatites, genesis and evolution: London, Unwin Hyman, p. 221-254.

Ferguson, J., 1970, The differentiation of agpaitic magmas: The Ilímaussaq intrusion, South Greenland: Canadian Mineralogist, v. 10, p. 335-394.

Fitton, J.G., and Upton, B.G.J., 1987, Alkaline igneous rocks: Oxford, Blackwell, p. 558-559.

Freestone, I.C., and Hamilton, D.L., 1980, The role of liquid immiscibility in the genesis of carbonatites - an experimental study: Contributions to Mineralogy and Petrology, v. 73, p. 105-117.

Gaffey, S.J., 1985, Reflectance spectroscopy in the visible and near-infrared $(0.35-2.55 \mathrm{um})$ : Applications in carbonate petrology: Geology, v. 13, p. $270-273$

Gao, B.C., Heidebrecht, K.B., and Goetz, A.F.H., 1993, Derivation of scaled surface reflectances from AVIRIS data: Remote Sensing of Environment, v. 178 , p. $165-178$.

Gao, B.C., Montes, M.J., Davis, C.O., and Goetz, A.F.H., 2009, Atmospheric correction algorithms for hyperspectral remote sensing data of land and ocean: Remote Sensing of Environment, v. 113, p. S17-S24.

Garson, M.S.S., 1965, Carbonatites of southern Malawi: Bulletin of the Geological Survey of Malawi, v. 15, p. 1-128.

Gittins, J., 1989, The origin and evolution of carbonatite magmas, in Bell, K., ed., Carbonatites, genesis and evolution: London, Unwin Hyman, p. $580-600$

Goetz, A.F.H., 2009, Three decades of hyperspectral remote sensing of the Earth: A personal view: Remote Sensing of Environment, v. 113, p. S5-S16.

Goetz, A.F.H., Vane, G., Solomon, J.E., and Rock, B.N., 1985, Imaging spectrometry for Earth remote sensing: Science, v. 228, p. 1147-1153.

Görller-Walrand, C., and Binnemans, K., 1998, Spectral intensities of f-f transitions, in Schneidner, K.A.G., and Eyring, L., eds., Handbook on the Physics and Chemistry of Rare Earths: Amsterdam, Elsevier, p. 101-264.

Green, R.O. et al., 1998, Imaging spectroscopy and the Airborne Visible/ Infrared Imaging Spectrometer (AVIRIS): Remote Sensing of Environment, v. 65 , p. $227-248$.

Guanter, L. et al., 2015, The EnMAP spaceborne imaging spectroscopy mission for Earth observation: Remote Sensing, v. 7, p. 8830-8857.

Harmer, R.E., and Gittins, J., 1998, The case for primary, mantle-derived carbonatite magma: Journal of Petrology, v. 39, p. 1895-1903.

Hatch, G.P., 2012, Dynamics in the global market for rare earths: Elements, v. 8, p. 341-346

Hook, S.J., and Kahle, A.B., 1996, The micro Fourier transform interferometer ( $\mu$ FTIR - a new field spectrometer for acquisition of infrared data of natural surfaces: Remote Sensing of Environment, v. 56, p. 172-181.
Hook, S.J., Karlstrom, K.E., Miller, C.F., and McCaffrey, K.J.W., 1994 Mapping the Piute Mountains, California, with thermal infrared multispectral scanner (TIMS) images: Journal of Geophysical Research, v. 99, p. $15605-15622$.

Hornig-Kjarsgaard, I., 1998, Rare earth elements in Sövitic carbonatites and their mineral phases: Journal of Petrology, v. 39, p. 2105-2121.

Huang, Y.-M., Hawkesworth, C.J., van Calsteren, P., and McDermott, F., 1995, Geochemical characteristics and origin of the Jacupiranga carbonatites, Brazil: Chemical Geology, v. 119, p. 79-99.

Hugenholtz, C., 2012, Small unmanned aircraft systems for remote sensing and earth science research: EOS, v. 93, p. 24-25.

Jones, A.P., and Larsen, L.M., 1985, Geochemistry and REE minerals of nepheline syenites from the Motzfeldt centre, south Greenland: American Mineralogist, v. 70, p. 1087-1100.

Kahle, A.B., and Alley, R.E., 1992, Separation of temperature and emittance in remotely sensed radiance measurements: Remote Sensing of Environment, v. 111, p. 107-111.

Kerr, A., Rafuse, H., Sparkes, G., Hinchey, J., and Sandeman, H., 2011, Visible/infrared spectroscopy (VIRS) as a research tool in economic geology: Background and pilot studies from Newfoundland and Labrador: Geological Survey of Canada Report 11-1, p. 145-166.

Korb, A.R., Dybwad, P., Wadsworth, W.J., and Salisbury, J.W., 1996, Portable Fourier transform infrared spectroradiometer for field measurements of radiance and emissivity.: Applied Optics, v. 35, p. 1679-1692.

Kramer, H.J., 2002, Observation of the earth and its environment: Survey of missions and sensors: Berlin Heidelberg, Springer-Verlag.

Kruse, F.A., 2012, Mapping surface mineralogy using imaging spectrometry: Geomorphology, v. 137, p. 41-56.

Le Bas, M.J., Le Maître, R.W., Streckeisen, A., and Zanettin, B., 1986, A chemical classification of volcanic rocks based on the total alkali-silica diagram: Journal of Petrology, v. 27, p. 745-750

Le Maître, R.W., 2002, Igneous rocks: A classification and glossary of terms: Cambridge, Cambridge University Press.

Liu, G., 2005, Electronic energy level structure, in Hull, R., Parisi, J., Osgood, R.M., Warlimont, H., Liu, G., and Jacquier, B.,eds., Spectroscopic properties of rare earths in optical materials: Berlin, Springer, p. 1-94.

Lottermoser, B.G., 1990, Rare-earth element mineralisation within the Mt.Weld carbonatite laterite, Western Australia: Lithos, v. 24, p. 151-167.

Mariano, A.N., 1989, Nature of economic mineralisation in carbonatites and related rocks, in K.Bell, ed., Carbonatites, genesis and evolution: London, Unwin Hyman, p. 149-176.

Mars, J.C., and Rowan, L.C., 2011, ASTER spectral analysis and lithologic mapping of the Khanneshin carbonatite volcano, Afghanistan: Geosphere, v. 7 , p. $276-289$.

McCormick, G.R., and Le Bas, M.J., 1996, Phlogopite crystallization in carbonatitic magmas from Uganda: Canadian Mineralogist, v. 34, p. 469-478.

McCreath, J.A., Finch, A.A., Herd, D.A., and Armour-Brown, A., 2013, Geochemistry of pyrochlore minerals from the Motzfeldt center, south Greenland: The mineralogy of a syenite-hosted Ta, Nb deposit: American Mineralogist, v. 98 , p. $426-438$.

Mitchell, R.H., 2005, Carbonatites and carbonatites and carbonatites: Canadian Mineralogist, v. 43, p. 2049-2068.

2015, Primary and secondary niobium mineral deposits associated with carbonatites: Ore Geology Reviews, v. 64, p. 626-641.

Nicodemus, F.E., 1965, Reflectance nomenclature and directional reflectance and emissivity: Applied Optics, v. 7, p. 767-775.

Ninomiya, Y., Fu, B., and Cudahy, T.J., 2005, Detecting lithology with advanced spaceborne thermal emission and reflection radiometer (ASTER) multispectral thermal infrared "radiance-at-sensor" data: Remote Sensing of Environment, v. 99, p. 127-139.

Olson, J.C., Shawe, D.R., Pray, L.C., and Sharp, W..N., 1954, Rare-earth mineral deposits of the Mountain Pass district, San Bernardino County, California.: Science, v. 119, p. 325-326.

Oppenheimer, C., 1998, Satellite observation of active carbonatite volcanism at Ol Doinyo Lengai, Tanzania: International Journal of Remote Sensing, v. 19 , p. $55-64$

Rankin, A.H., 1977, Fluid-inclusion evidence for the formation conditions of apatite from the Tororo carbonatite complex of eastern Uganda: Mineralogical Magazine, v. 41, p. 15.5-164.

Ribeiro Da Costa, I., Rodrigues, P.C.R., Barriga, F.J.A.S., Rona, P.A., Nunes, C.D., and Vaz, P.D., 2013, Colourless aegirine in metamorphic rocks from Bayan Obo (Inner Mongolia): Lack of charge transfer transitions as possible explanation: European Journal of Mineralogy, v. 25, p. 987-993. 
Rowan, L.C., and Mars, J.C., 2003, Lithologic mapping in the Mountain Pass, California area using advanced spaceborne thermal emission and reflection radiometer (ASTER) data: Remote Sensing of Environment, v. 84, p. 350-366.

Rowan, L.C., Kingston, M.J., and Crowley, J.K., 1986, Spectral reflectance of carbonatites and related alkalic igneous rocks: Selected samples from four North American localities: Economic Geology, v. 81, p. 857-871.

Rowan, L.C., Bowers, T.L., Crowley, J.K., Anton-Pacheco, C., Gumiel, P., and Kingston, M.J., 1995, Analysis of Airborne Visible-Infrared Imaging Spectrometer (AVIRIS) data of the Iron Hill, Colorado, carbonatite-alkalic igneous complex: Economic Geology, v. 90, p. 1966-1982.

Simonetti, A., and Bell, K., 1994, Isotopic and geochemical investigation of the Chilwa Island carbonatite complex, Malawi: Evidence for a depleted mantle source region, liquid immiscibility, and open-system behaviour: Journal of Petrology, v. 35, p. 1597-1621.

Smith, M.O., Adams, J.B., and Johnson, P.E., 1985, Quantitative determination of mineral types and abundances from reflectance spectra using principal components analysis: Journal of Geophysical Research, v. 90, p. C797-C804.

Smith, M.P., Henderson, P., and Campbell, L.S., 2000, Fractionation of the REE during hydrothermal processes: Constraints from the Bayan Obo FeREE-Nb deposit, Inner Mongolia, China: Geochimica et Cosmochimica Acta, v. 64, p. 3141-3160.

Smith, M.P., Campbell, L.S., and Kynicky, J., 2015, A review of the genesis of the world-class Bayan Obo Fe-REE-Nb deposits, Inner Mongolia, China: Multistage processes and outstanding questions: Ore Geology Reviews, v. 64 , p. $459-476$.

Stuffler, T. et al., 2007, The EnMAP hyperspectral imager-an advanced optical payload for future applications in Earth observation programmes: Acta Astronautica, v. 61, p. 115-120.

Swinden, H.S., and Siegfried, P., 2011, Amended 43-101 technical report on the rare earth element occurrences in the Lofdal carbonatite complex, Kunene region, Khorixas district, Namibia: Halifax, Swinden Geoscience Consultants Ltd., 210 p.

Tappe, S., Foley, S.F., Stracke, A., Romer, R.L., Kjarsgaard, B.A., Heaman, L.M., and Joyce, N., 2007, Craton reactivation on the Labrador Sea margins: ${ }^{40} \mathrm{Ar} /{ }^{39} \mathrm{Ar}$ age and $\mathrm{Sr}-\mathrm{Nd}-\mathrm{Hf}-\mathrm{Pb}$ isotope constraints from alkaline and carbonatite intrusives: Earth and Planetary Science Letters, v. 256, p. $433-454$

Tappe, S., Steenfelt, A., Heaman, L.M., and Simonetti, A., 2009, The newly discovered Jurassic Tikiusaaq carbonatite-aillikite occurrence, West Greenland, and some remarks on carbonatite-kimberlite relationships: Lithos, v. 112 , p. 385-399.

Ting, W., Rankin, A.H., and Woolley, A.R., 1994, Petrogenetic significance of solid carbonate inclusions in apatite of the Sukulu carbonatite, Uganda: Lithos, v. 31, p. 177-187.
Turner, D.J., Rivard, B., and Groat, L.A., 2014, Visible and short-wave infrared reflectance spectroscopy of REE fluorocarbonates: American Mineralogist, v. 99, p. 1335-1346.

Vartiainen, H., and Paarma, H., 1979, Geological characteristics of the Sokli carbonatite complex, Finland: Economic Geology, v. 74, p. 1296-1306.

Veraverbeke, S., Stavros, E.N., and Hook, S.J., 2014, Assessing fire severity using imaging spectroscopy data from the Airborne Visible/Infrared Imaging Spectrometer (AVIRIS) and comparison with multispectral capabilities: Remote Sensing of Environment, v. 154, p. 153-163.

Wall, F., 2014, Rare earth elements, in Gunn, G., ed., Critical metals handbook: Oxford, John Wiley and Sons, p. 312-339.

Wall, F., and Mariano, A.N., 1996, Rare earth minerals in carbonatites: A discussion centered on the Kangankunde carbonatite, Malawi, in Jones, A.P., Wall, F., and Williams, C.T., eds., Rare earth minerals: Chemistry, origin and ore deposits: London, Chapman and Hall, p. 193-225.

Wall, F., and Zaitsev, A.N., 2004, Rare earth minerals in Kola carbonatites, in Wall, F., and Zaitsev, A.N., eds., Phosphorites and carbonatites from mantle to mine: The key example of the Kola alkaline province: Mineralogical Society Series 10, p. 341-373.

Wallace, M.E., and Green, D.H., 1988, An experimental determination of primary carbonatite magma composition: Nature, v. 335, p. 343-346.

Williams, C.E., 1952, Carbonatite structure: Tororo Hills, eastern Uganda: Geological Magazine, v. 89, p. 286.

Woolley, A.R., and Kempe, D.R.C., 1989, Carbonatites: Nomenclature, average chemical compositions, and element distribution, in Bell, K., ed., Carbonatites, genesis and evolution: London, Unwin Hyman, p. 1-14.

Woolley, A.R., and Kjarsgaard, B.A., 2008, Paragenetic types of carbonatite as indicated by the diversity and relative abundances of associated silicate rocks: Evidence from a global database: Canadian Mineralogist, v. 46 p. $741-752$.

Woolley, A.R., Barr, M.W.C., Din, V.K., Jones, G.C., Wall, F., and Williams, C.T., 1991, Extrusive carbonatites from the Uyaynah area, United Arab Emirates: Journal of Petrology, v. 32, p. 1143-1167.

Yang, K.F., Fan, H.R., Santosh, M., Hu, F.F., and Wang, K.Y., 2011, Mesoproterozoic carbonatitic magmatism in the Bayan Obo deposit, Inner Mongolia, North China: Constraints for the mechanism of super accumulation of rare earth elements: Ore Geology Reviews, v. 40, p. 122-131.

Zaitsev, A.N., Demeny, A., Sindern, S., and Wall, F., 2002, Burbankite group minerals and their alteration in rare earth carbonatites - source of elements and fluids (evidence from $\mathrm{C}-\mathrm{O}$ and Sr-Nd isotopic data): Lithos, v. 62 p. $15-33$. 
APPENDIX
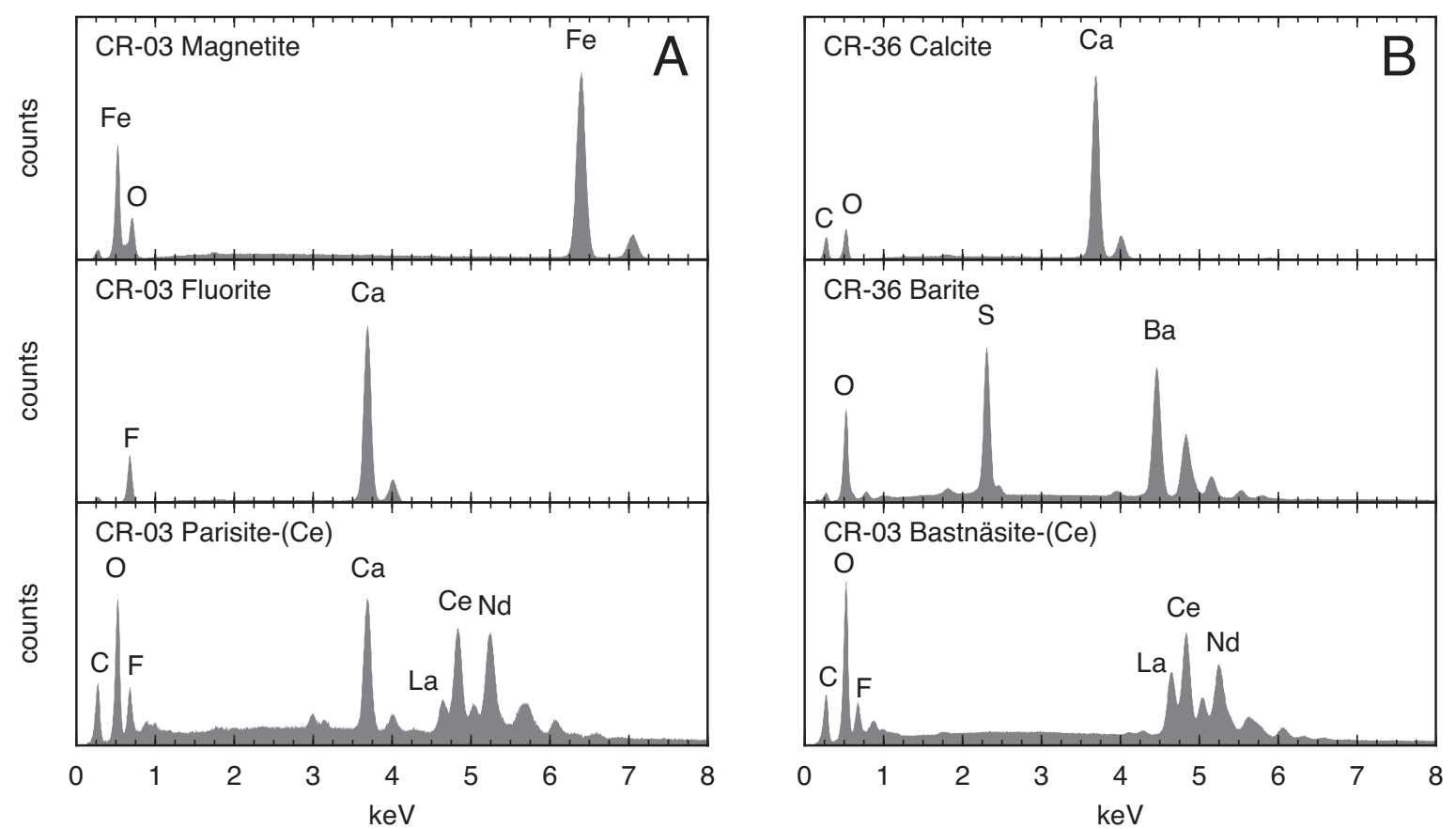

号

$\stackrel{0}{\stackrel{0}{5}}$
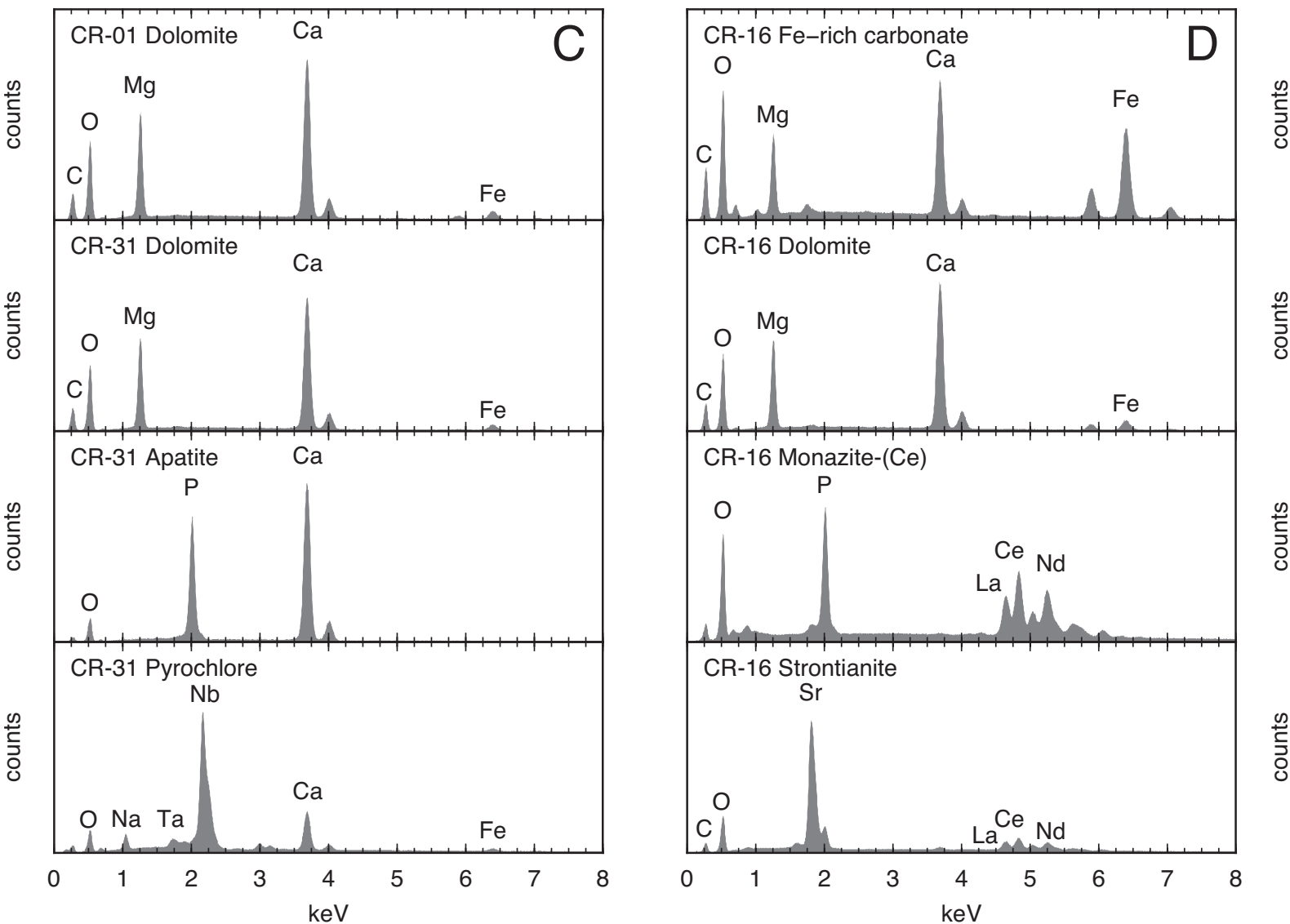

Fig. A1. Characteristic energy dispersive X-ray (EDX) spectra collected from a range of rock-forming and REE minerals. Peaks used for mineral identification are labeled according to element. 

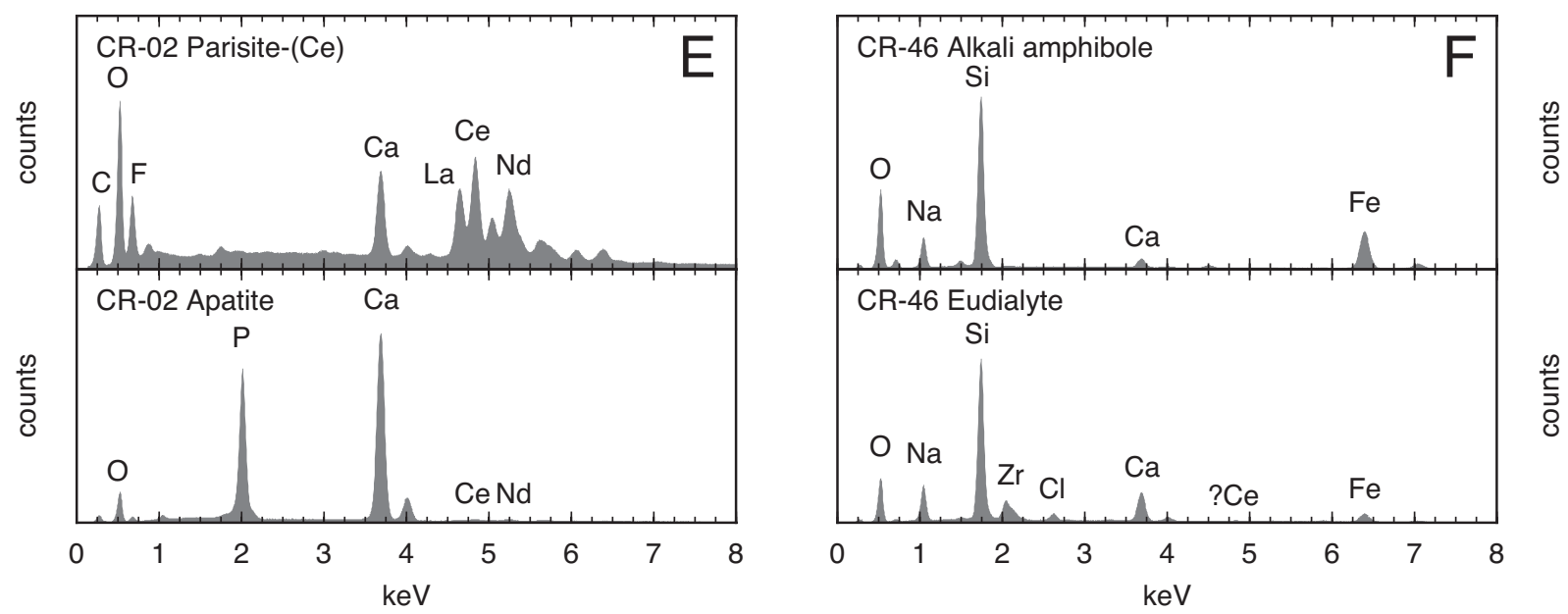

Fig. A1. (Cont.)
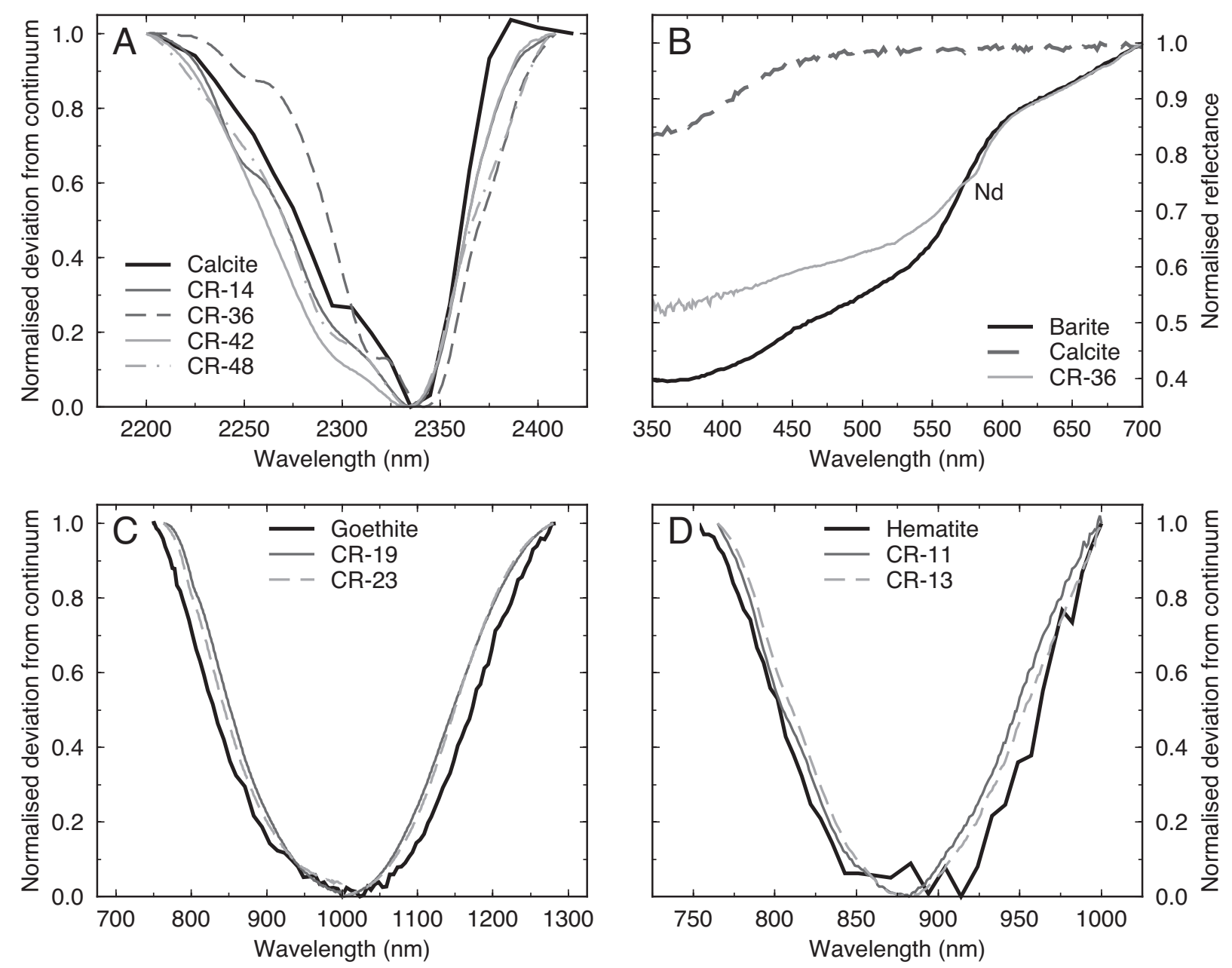

Fig. A2. A. Normalized continuum-removed spectra of $\mathrm{CO}_{3}$ absorptions in a range of carbonate-rich samples compared with a calcite reference spectrum (Clark et al., 2007). All spectra show reflectance minima at $\sim 2,330 \mathrm{~nm}$. B. Normalized spectra of barite-rich, calcite-bearing CR-36 from Mountain Pass compared with barite and calcite reference spectra (Clark et al., 2007). The location of inflection points in the CR-36 spectrum are consistent with barite dominating the spectral signal, not calcite. A small additional absorption at $~ 583 \mathrm{~nm}$ can be attributed to Nd. C. Normalized continuum-removed spectra showing Fe absorptions in CR-19 and CR-23 from Kaiserstuhl and Songwe compared with a reference goethite spectrum (Clark et al., 2007). D. Normalized continuum-removed spectra showing Fe absorptions in CR-11 and CR-13 from Motzfeldt compared with a reference hematite spectrum (Clark et al., 2007). 
